\title{
Determinants of Asymmetric Return Comovements of Gold and other Financial Assets
}

Sunil S. Poshakwale ${ }^{1}$ and Anandadeep Mandal ${ }^{2}$

${ }^{1}$ Corresponding author: Centre for Research in Finance, School of Management, Cranfield University, England, MK43 0AL.

Phone: +44 (0)1234 754404, e-mail: sunil.poshakwale@ cranfield.ac.uk

${ }^{2}$ University of Derby, England, DE1 3LD.

Phone: +44(0)1332597966, e-mail: a.mandal@ derby.ac.uk 


\title{
Determinants of Asymmetric Return Comovements of Gold and other Financial Assets
}

\begin{abstract}
Using conditional time-varying copula models, we characterize the dependence structure of return comovements of gold and other financial assets (stocks, bonds, real estate and oil) during economic expansion and contraction regimes. We also investigate which key macroeconomic and non-macroeconomic variables significantly impact the asset return comovements using a two stage Markov Switching Stochastic Volatility (MSSV) framework. Our results show that the non-macro variables have significant influence on the return comovements. We find that gold is an inappropriate hedge against interest rate changes for real-estate and oil-based portfolios, while for bond portfolios, gold offers a good hedge against inflation uncertainty. We also provide evidence that the "flight to safety" phenomenon is due to the implied volatility of the stock market, rather than the observed stock market uncertainty. Finally, we forecast the asset return comovements and examine their economic significance. We show that a dynamic MSSV model which includes the macroeconomic and non-macroeconomic variables yields superior forecast of future asset return comovements when compared with a multivariate conditional covariance model.
\end{abstract}

JEL classification: C32, C58, C51, G17

Keywords: Gold, Asset return comovements, forecasting, Markov Switching stochastic volatility model, dependence structure 


\section{Introduction}

In the wake of the economic downturn during 2007-08, returns of different asset classes have shown evidence of strong linkages. Declining house prices in the US led to the collapse of various financial institutions, triggering a steep decline in equity markets, commodity prices and real estate values globally. The oil prices also witnessed high volatility with prices reaching US\$147 per barrel in July 2008 and dropping below US\$60 per barrel within the next four months (Chan et al., 2011). In addition, the stimulated response by the Federal Reserve led to extremely low interest rates in many economies, driving up the demand for government bonds and causing a steep decline in yields. On the other hand, corporate bond spreads widened appreciably whilst the gold prices reached new highs.

These developments provide anecdotal evidence of increased linkages between financial, commodities and real estate markets, triggering a renewed interest amongst academics and practitioners in examining asset allocation strategies for effective diversification of risk during turbulent economic conditions. However, asset allocation strategies can be properly executed only if the nature of return comovements of various asset returns is well understood. Guidolin and Timmermann (2007) show that since asset return comovements are time varying and dynamic in nature, investors require information about conditional distribution of the asset returns for implementing dynamic asset allocation strategies. Further, asset return comovements change due to changes in economic conditions and/or changes in non-macroeconomic factors. For example, Piplack and Straetmans (2010) show that asset return comovements change during periods of market stress. Thus, in constructing an optimal portfolio, it is critical to identify the economic circumstances and understand the impact of macro and non-macro factors on asset return comovements.

While extant literature extensively studies the return comovements of conventional financial assets such as stocks and bonds, research on return comovements of other financial assets is sparse. In particular, despite the importance of gold as a hedge and/or a safe haven, studies investigating the dependence structure of gold returns and other assets are rare. Amongst them, the prominent studies by Tully and Lucey (2007) and Batten and Lucey (2009) model the volatility of gold futures market, while Baur (2012) examine the asymmetric nature of gold 
volatility. These studies analyze some specific volatility characteristics of gold, but do not focus on examining the dependence structure of gold returns with other assets. Far fewer studies examine the relationship between gold and other financial assets. Exceptions include Baur and Lucey (2010) and Baur and McDermott (2010). They demonstrate that gold acts as a safe-haven investment in volatile market conditions. Yet, in extreme market conditions Treasury bond returns and not gold are negatively correlated to stock returns (Piplack \& Straetmans, 2010). Fewer studies examine the correlation between gold and other asset returns. Cashin et al. (2002) show that there exists significant correlation between oil and gold for the period 1960 to 1985 . Pindyck and Rotemberg (1990) confirm similar findings for oil and gold price levels. Šimáková (2011) shows that there exists a long term relationship between gold and oil prices. However, research examining the economic sources that impact the relationship between gold and other asset returns is sparse. Most of these studies exhibit the link between gold and oil prices through inflation channel. The studies empirically show that when inflation rises, the price of gold as a good also rises (Hooker, 2002; Hunt, 2006). Furlong et al. (1996) find that increase in oil prices positively affects prices of all other assets. Most interestingly, none of these existing studies analyze the extreme comovements of gold and other asset returns.

Therefore, a model capable of capturing the time varying linkages between gold and other financial assets and the effects of macroeconomic and non-macro factors influencing the dependence structures of the return comovements is required. For instance, if market linkages between gold and other financial assets increases in times of economic crisis, then the effectiveness of gold as safe haven may be compromised. Alternatively, if the dependence decreases in periods of economic contraction, the diversification benefit of investing in gold is enhanced.

Against this backdrop, the paper makes new and incremental contributions to the existing literature in the following ways. First, while research widely acknowledges that return distributions of financial assets are non-normal, the extant literature primarily uses linear dependence measure to examine the asset market linkages. Even though the linear dependence structure is simple to use, it fails to accurately characterize the non-normal distributions of the asset returns (Jondeau \& Rockinger, 2006). We, therefore, use dynamic conditional copula 
model for characterizing the regime switching dependence structure of gold and other asset return comovements during different economic regimes. Second, in contrast to previous studies we use a two stage Markov switching stochastic volatility (MSSV) framework which enables us to capture the dynamics and the structural changes in the state variables in forecasting the return comovements. Third, using the key determinants, the paper examines the performance of copula based models for forecasting the gold-paired asset return comovements. Finally, we demonstrate how investors with different risk appetite may be able to use our proposed approach for making optimal portfolio choices.

Our paper reports several key findings. First, we confirm that the dependence structures of gold and other asset return comovements show significant regime-switching behavior both in terms of statistical and economic significance, which corresponds to periods of economic expansion and economic. Importantly, the transition probabilities of the different regimes indicate that investment in gold leads to risk diversification. Second, examining the factor contributions, we find that the model fit worsens considerably when the non-macro factors are dropped for the all the pairs except for gold- real estate pair. This signifies the importance of considering the impact of economic uncertainty in asset allocation for portfolio diversification. Third, we show that rise in interest rates, has a positive impact on gold-oil and gold-real estate return comovements. This suggests that gold is an inappropriate hedge against interest rate changes for real-estate and oilbased portfolios. Fourth, we find that inflation positively impacts the return comovements of all asset pairs except for the gold and real estate. This implies that gold is a good hedge against inflation for real estate based investments. Fifth, amongst the non-macro variables we find that uncertainty parameters and the illiquidity variables are significant. In particular, we show that for bond portfolios, gold makes a good hedge against inflation uncertainty. Sixth, consistent with previous literature (Baur and Lucey, 2010; Baur and McDermott, 2010) we find evidence to support previously reported findings that gold acts as a safe-haven investment, particularly in volatile stock market conditions. Further, we show that during the economic contraction phase increase in demand for gold potentially triggers increase in bond investments. In contrast, the negative impact of bond illiquidity during either of the phases suggests that decrease in demand for bond indicates a rise in gold investments. Seventh, our findings suggest that the observed "flight to safety" phenomenon in the gold and equity market is due to the implied volatility of the 
stock market, rather than the observed stock market uncertainty. Further with the increase in risk aversion, the return comovements across gold and other assets also increases. Finally, our research shows that the dynamic strategy which incorporates regime switching framework outperforms the multivariate conditional covariance strategy in forecasting asset return comovements. Investors with different risk-appetites are able to enhance their portfolio optimization choices by utilizing the analytical approach proposed in the study.

The rest of the paper is organized as follows: Section 2 discusses the methodology employed to model the dynamics of the dependence structure models using the MSSV model and copula model and data used in the study. Section 3 discusses the empirical findings and finally Section 4 concludes the paper.

\section{Methodology and Data Used}

\subsection{The Dynamic Dependence Structure Model}

We employ a Markov Switching framework in investigating the dependence structure and allow each state variable to follow an evolutionary process which is presented in the following section. Although autoregressive conditional heteroskedasticity $(\mathrm{ARCH})$ models can be employed to tackle this issue (Bollerslev et al., 1988; Engle, 1982), the standard normally and independently distributed (NID) assumption of the error term is often violated in practice. We, therefore, specify a model for the state variables that allows each of the vectors to follow an independent stochastic volatility (ISV) process. The stochastic volatility (SV) specification builds in a timevarying variance process for each of the elements of the structural factors, by allowing the variance to be a latent process.

We specify the MS model, which defines the dependence structure $\left(y_{t}\right)$ as

$$
y_{t}=\sum_{l=1}^{L} \varphi_{l} S_{t} x_{l, t}^{S}+\varepsilon_{t}
$$

where $L$ denotes the number of switching coefficients, $X_{l, t}$ represents the explanatory state variables, $S_{t}$ represents the regime of the variable at time $t$, and $\varepsilon_{t} \sim P\left(\phi_{S_{t}}\right)$ with $p(\phi)$ as the probability density function of the innovations, defined by the vector $(\phi)$. Each of the 
independent state variables follows a Markov switching stochastic volatility (MSSV) process, which we discuss next.

Our aim is to make the model parsimonious and yet flexible. Therefore, in contrast to the ARCHtype models, we allow the log volatility of the state variables to evolve stochastically over time. Following the discrete convention (Ball and Torous, 1999; Shephard, 1996), we characterize the $\mathrm{SV}$ model as an extension of the time-diffusion process

$$
\Delta x_{t}=a+b x_{t-1}+\sigma_{t} x_{t-1}^{\gamma} \varepsilon_{t}
$$

where $\gamma$ represents the diffusion term, $\Delta x_{t}=x_{t}+x_{t-1}$ and $\varepsilon_{t}$ is the standard normal random variable. The residual of the above equation is $e_{t}=\sigma_{t} x_{t-1}^{\gamma} \varepsilon_{t}$. The model allows the volatility $(\sigma)$ to evolve stochastically, following a first-order autoregressive process

$$
\log \sigma_{t}^{2}=\omega+\varphi \log \sigma_{t-1}^{2}+\eta_{t}
$$

where $\eta_{t} \sim N\left(0, \sigma_{\eta}^{2}\right), i . i . d$. is the disturbance term. It makes the variance subject to random shocks, making the process stochastic. We transform the residuals in equation (2) to $e_{t}=\Delta x_{t}-$ $a-b x_{t-1}$, which allows us to formulate a quasi-likelihood function by employing Kalman filtering. The log of the squared residuals is

$$
\log e_{t}^{2}=\log \sigma_{t}^{2}+2 \gamma \log x_{t-1}+\log \varepsilon_{t}^{2}
$$

Considering $z_{t}=\log e_{t}^{2}$ and $g_{t}=\log \sigma_{t}^{2}$ equation (13) reduces to

$$
z_{t}=g_{t}+2 \gamma \log x_{t-1}+\log \varepsilon_{t}^{2}
$$

where $g_{t}=\omega+\varphi g_{t-1}+\eta_{t}$. Next, we discuss the MSSV model, which is employed to examine the dynamics of the dependence structure.

This is a generalization of the SV and the MS model. This model allows the volatility to vary across different regimes. Since assumption of constant volatility in the regimes will either underestimate or overestimate volatility, the MSSV model enables different estimates of the elasticity of variance $(\gamma)$. We define the MSSV model as 


$$
\begin{gathered}
z_{t}=g_{t}+2 \gamma \log x_{t-1}+\log \varepsilon_{t}^{2} \\
g_{t}=\omega_{m}+\varphi g_{t-1}+\eta_{t}
\end{gathered}
$$

In contrast to classical SV model, in the above equation we define $\omega_{m}=\log \sigma_{m}^{2}$, which allows us to capture different regimes at a particular point in time. With the regimes governing the dynamic behaviour of the estimated state variables, we condition a particular regime and calibrate the density of the variable of interest. In this parameterization of the MS model, the transition probabilities from state $\mathrm{m}$ to state $\mathrm{n}$ in time $\mathrm{t}$ are defined as $p_{m n}=\operatorname{Pr}\left[S_{t}=m \mid S_{t-1}=\right.$ $n]$. It should be noted that for $m=1, \ldots, M$, only $M(M-1)$ needs to be specified as $p_{m n}=$ $\operatorname{Pr}\left[S_{t}=M \mid S_{t-1}=n\right]=1-\sum_{m=1}^{M-1} \operatorname{Pr}\left[S_{t}=m \mid S_{t-1}=n\right]$. In our model we allow the unconditional volatility to change between different states by allowing $\left(\sigma_{i}\right)$ in equation (2) to take values of $m \in\{1, \ldots, M\}$ at time $t$. The corresponding equation transforms to

$$
\Delta x_{t}=a+b x_{t-1}+\sigma_{m} x_{t-1}^{\gamma} \varepsilon_{t}
$$

An important component of the structure of the MS model is that the switching of the states follows a stochastic process. Thus, identifying states based on distributional characteristics of the regime switching variable, such as $(\mu \pm \sigma)$, i.e. mean plus or minus standard deviation, would lead to a restricted form of the switching model failing to capture the true dynamics of the dependence structure. However, a weak regime classification will imply that the model is unable to successfully distinguish between the regimes from the behaviour of the data, leading to misspecification. In order to address this issue, we identify the regimes based on regime switching classification. An ideal switching model should classify the regimes sharply, i.e. the regime transition probabilities $\left(p_{m n}\right)$ should be close to 0 or 1. Based on Ang and Bekaert (2002) we construct the regime classification statistic (RCS) for M states as

$$
R C S(M)=100 M^{2} \frac{1}{T} \sum_{t=1}^{T}\left(\prod_{m=1}^{M} p_{m t}\right)
$$

where $p_{m t}=\operatorname{Pr}\left(S_{t}=m \mid I_{T}\right)$ indicates the regime transition probabilities and $100 M^{2}$ serves as a normalizing constant to keep the statistic between 0 and 100. A value of 0 signifies perfect regime classification, whereas a value of 100 implies that the regimes are not capable of distinguishing the behaviour of the data, i.e. dependence structure, across the defined regimes and hence they are irrelevant. 
We use Kalman filter for estimating the MSSV model. However, the above procedures make the process exclusively path dependent. Hence, to remove the path dependence we compute the conditional expectation of the log-volatility forecast by taking the weighted average output of the previous iteration. We then calculate the regime probabilities based on Smith's (2002) modification of Hamilton's (1989) filter (the estimation process is explained in Appendix A).

In order to robustly examine the forecasting of asset return comovements, it is essential to consider a reasonably adequate hold-off sample period. Therefore, we choose 16 years of observation to estimate the model parameters and forecast returns comovements for 9 years. Moreover, since it is not a prior assumption that our switching model outperforms a single regime model, forecasting is repeated for different subsamples. In essence, we fit the model for 4 years and estimate one step ahead forecast, delete the first observation and add the next one and then again re-estimate a one-step ahead forecast. In order to evaluate the possible changes in the pattern of the asset return comovements, we carry out forecasting exercise for two subsamples. In the first one, we estimate the model for the period 1987 to 2002 and forecast return comovements for 2003 to 2012 period. For the second part estimate the model for 2003 to 2012 and forecast return comovements for 1987 to 1996 period.

To investigate the quality of the forecast, the median of squared errors are calibrated for both the regime switching MSSV model and the non-regime switching stochastic volatility model. Further, based on Pagan and Schwert (1990) we run a forecast efficiency regression to examine whether the regime switching model outperforms the non-regime model (NRM). We model the forecast efficiency regression as $v_{r c, t}=\alpha+\beta \hat{v}_{r c, t}+\epsilon_{t}$. In this framework, if the mean and the variance forecast of the asset return comovements $\left(v_{r c, t}\right)$ are unbiased, then the regression implies that $\alpha=0$ and $\beta=1$. To test the forecasting efficiency, the regression model is estimated using ordinary least square wherein standard errors are corrected for autocorrelation and heteroskedastic following Newey and West (1987). Further, we correct the standard errors for the uncertainty originating from the estimation of the factors. Since we use a rolling sample for our forecasting, based on West and McCracken (1983) we multiply the Newey-West standard errors by $\sqrt{\left(1-\pi^{2} / 3\right)}$, where $\pi=10 / 16$, i.e. forecasting period by parameter estimation period. 


\subsection{Estimating the State Variables}

We consider a variety of macro and non-macroeconomic variables for forecasting the return comovements that have been used in the existing literature. We include three macro-economic factors: risk free rate $\left(r f_{t}\right)$, output gap $\left(o_{t}\right)$, and inflation $\left(i_{t}\right)$. These variables predominantly affect both cash flows and discount rates and hence affect asset values (d'Addona and Kind, 2006). However, it is not always easy to predict their precise impact on asset returns. Since interest rates affect most of the variations in asset returns, we include nominal risk-free rate. To capture the impact of long term interest rates, we include nominal risk-free rate, expected inflation and term premium. In order to capture the effect of the term premium and the inflation premium we use two direct 'economic' risk proxies i.e., output uncertainty $\left(o u_{t}\right)$, inflation uncertainty $\left(i u_{t}\right)$. Further, liquidity affects asset prices in two central ways. First, in illiquid markets, beta may fail to quickly respond to economic shocks. Second, economic shocks that increase liquidity may have a positive impact on asset returns. Moreover, monetary policy can affect liquidity in financial markets. It may increase borrowing constraints and/or trigger trading activity, influencing asset return comovements. Existing studies by Chordia et al. (2005) and Goyenko et al. (2009) are rather inconclusive about the liquidity effects. To address this issue, we consider unconstrained proxies of use bond, stock and gold market illiquidity shocks in our model. We capture stock market illiquidity $\left(l r_{t}\right)$ by using capitalization-based proportion of zero daily returns across all listed firms in the US market, i.e. Standard and Poor's (S\&P) 500 index and for bond market illiquidity $\left(d s_{t}\right)$, we use bid-ask spreads across all securities, i.e. one month, three months, and one, two, three, five, seven, ten, twenty and thirty years of maturity.

Plosser and Rouwenhorst (1994) and Estrella and Hardouvelis (2012) use the term spread $\left(t s_{t}\right)$ as a leading indicator of economic activity. Yet, more recent evidence shows that the spread is not as informative as it has been in the past. In particular, Dotsey (1998) and Henry et al. (2004) show that the relationship between business cycles and economic output behave asymmetrically. Ocal (2006) provides evidence of asymmetric relations between economic output and growth. Therefore, the existence of a non-linear relationship between these variables is more likely. We use an alternative measure to capture the different regimes of the business cycle. Our measure of 
modified depth of recession $\left(d r_{t}\right)$ is based on Lee and Wang's (2012) estimate of business cycle proxy. This measure enables us to study its impact for both recession and expansion regimes.

Our model, thus, includes the following economic state variables: the risk free rate $\left(r f_{t}\right)$, output gap $\left(o_{t}\right)$, inflation $\left(i_{t}\right)$, and risk aversion $\left(r a_{t}\right)$ and eight non-macroeconomic variables, i.e. output uncertainty $\left(o u_{t}\right)$, inflation uncertainty $\left(i u_{t}\right)$, gold market illiquidity $\left(g i l r_{t}\right)$, bond market illiquidity $\left(d s_{t}\right)$, equity market illiquidity $\left(l r_{t}\right)$, variance premium $\left(v p_{t}\right)$, term spread $\left(t s_{t}\right)$ and the depth of recession $\left(d r_{t}\right)$. We collect these variables in a vector $\left(K_{t}\right)$ to identify our explanatory structural factors $\left(X_{t}\right)$. Appendix B provides a description and the construction method of these state variables.

We use a two-stage structural framework to examine the influence of these state variables on the joint dependence structure. This approach has three key economic implications i) it allows the dynamics of the state variables to depend on the expectations of future values as is true in cases of macro-models, ii) it captures the contemporaneous correlation between the fundamental state variables and, iii) it captures the structural changes in the macro-economic relationships. Further, we impose structural restrictions inspired by New-Keynesian dynamics in identifying the macroeconomic variables which also accommodate for heteroskedastic shocks. Appendix B provides the description of the variables used.

For identifying structural shocks, we split the state variables into two sets: i) "macro variables $(m v) ", K_{t, m v}=\left[r f_{t}, o_{t}, i_{t}, r a_{t}\right]^{\prime} \quad$ and ii) "other variables $(o v)$ ", $\quad$ i.e. $K_{t, o v}=$ $\left[o u_{t}, i u_{t}, g i l r_{t}, d s_{t}, l r_{t}, v p_{t}, t s_{t}, d r_{t}\right]^{\prime}$. The 'other variables' (ov) include the non-macroeconomic variables. For modelling $K_{t, m v}$ we employ a New Keynesian model, which we discuss below. To identify the $K_{t, o v}$ shocks we characterize a simple empirical model where $o v$ depend on $m v$.

Following Bekaert et al.'s (2010) New-Keynesian model, we formulate the structural model for $X_{t, m v}$. The model comprises three equations i) the demand (IS) equation, ii) the aggregate supply $(A S)$ equation and iii) the forward feeding monetary policy $(M P)$ rule. This allows us to capture the time-varying risk aversion dynamics in the structural model. 


$$
\begin{gathered}
r f_{t}=\alpha_{M F}+\tau r f_{t-1}+(1-\tau)\left[a\left(S_{t}^{M P}\right) E_{t}\left(i_{t+1}\right)+b\left(S_{t}^{M P}\right) o_{t}\right]+X_{t}^{r f} \\
o_{t}=\alpha_{I S}+\omega E_{t}\left(o_{t+1}\right)+(1-\omega) o_{t-1}+\theta r a_{t}-\varphi\left(r f_{t}-E_{t}\left(i_{t+1}\right)\right)+X_{t}^{o} \\
i_{t}=\alpha_{A S}+\lambda E_{t}\left(i_{t+1}\right)+(1-\lambda) i_{t-1}+\varphi o_{t}+X_{t}^{i} \\
r a_{t}=\beta_{r a}+\gamma r a_{t-1}+X_{t}^{r a}
\end{gathered}
$$

The parameter $(\tau)$ in the equation (8) represents the forward-looking monetary policy smoothing estimate. Cho and Moreno (2006) show that changes in monetary policy significantly influence macro dynamics and structural shocks. We, therefore, introduce a standard Markov-chain process that allows the monetary policy to vary across two regimes $\left(S_{t}^{M P}\right)$ with constant transition probabilities.

The parameters $(\omega)$ and $(\lambda)$ in the equations (9) and (10) represent the degree of IS and AS forward-looking behaviour respectively. The parameter $(\varphi)$ estimates the impact of real interest rate on the output gap and $(\phi)$ the effect of output gap on inflation. A high positive value of $\varphi$ and $\phi$ will indicate that monetary transmission mechanism has a significant influence on economy's output and inflation. The state variable $\left(r a_{t}\right)$ accommodates stochastic risk aversion to the demand equation of the New-Keynesian model that nests on Campbell and Cochrane's (1995) external habit model. In particular $\left(r a_{t}\right)$ represents the local curvature of the utility function. The parameter $(\theta)$ measures counteracting effect of consumption-smoothing and precautionary-savings of risk aversion on the real economy.

For the non-macroeconomic variables, we characterize the structural model as:

$$
K_{t, o v}=\alpha_{o v}\left(S_{t}\right)+\beta_{o v} K_{t-1, o v}+\sum_{o v}^{m v} K_{t, m v}+X_{t, o v}
$$

where $S_{t}$ represents the set of regime variables that drive the coefficient matrices. $K_{t, o v}$ is modelled based on Hamilton's (1989) specifications. $\beta_{o v}$ is a diagonal matrix, $\sum_{o v}^{m v}$ matrix is a $8 \times 4$ matrix, which appropriates contemporaneous covariance with the macro variables $K_{t, m v}$ and $X_{t, o v}$ is the vector of uncorrelated structural shocks of the "other variables". Employing Equation (12), the non-macroeconomic factors, may partially exhibit autoregressive dynamics of the macro-state variables. Further, $X_{t, o v}$ should be interpreted as non-macroeconomic variables 
related shocks. Finally, allowing the drifts to depend on the regime variable $S_{t}$ enables us to model the structural changes in the liquidity parameters (Hasbrouck, 2009).

\subsection{Estimation of the Dependence Structures}

We model return comovements based on the copula theory. Copula (C) is defined as a function that couples multiple distribution functions of Random Variables (RV) to their unidimensional unit-dimensional distribution function. Application of this cumulative distribution function (CDF) is derived from the Sklar Theorem (Sklar 1959). The theorem states that for a joint distribution function $H_{X, Y}(x, y)$ for all $x, y$, a function, copula $C(u, v)$, can be characterized in $\bar{R} \in(-\infty, \infty)$ such that $H_{X Y}(x, y)=C\left(F_{X}(x), F_{Y}(y)\right)$, where $F_{X}(x)$ and $F_{Y}(y)$ are the marginal distribution functions.

\subsubsection{Conditional Copula}

Let the conditional CDF of two RV (X and Y) and a given conditioning vector $\mathrm{K}$ be $H_{x y \mid k}(x, y \mid k)$ and the marginal distributions be $F_{x \mid k}(x \mid k)$ and $F_{y \mid k}(y \mid k)$. Then there exists a copula $\mathrm{C}$, such that

$$
H_{x y \mid k}(x, y \mid k)=C\left(F_{x \mid k}(x \mid k), F_{y \mid k}(y \mid k)\right)=C(u, v)
$$

where $(x, y \mid K)=k$ and $(x, y) \epsilon \bar{R} \times R$. In equation (13), $\mathrm{u}$ and $\mathrm{v}$ are the realizations of $U \equiv$ $F_{x \mid k}(x \mid k)$ and $V \equiv F_{y \mid k}(y \mid k)$, given $K=k$. U and $\mathrm{V}$ are the conditional probability integrals of the RV, X and Y (Sklar 1959).

Tail dependence allows us to capture the behaviour of the RV during periods of extreme events. It measures the probability of occurrence of extreme movements in one variable, given that the other variable witnesses an extreme deviation from the mean. In this study, we examine the tail dependence using the Modified Joe-Clayton (MJC) copula. Using MJC instead of a normal JoeClayton copula allows us to model the asymmetry of the tail dependence irrespective of the functional form of the copula used. The Joe-Clayton copula is defined as:

$C_{J C}\left(u, v \mid \tau^{U}, \tau^{L}\right)=1-\left(\left\{\left[1-(1-u)^{\theta}\right]^{-\delta}+\left[1-(1-v)^{\theta}\right]^{-\delta}-1\right\}^{-1 / \delta}\right)^{1 / \theta}$ 
where $\tau^{L}$ and $\tau^{U}$ are the probability of the RV in lower or upper joint tails respectively, $\theta=$ $1 / \log _{2}\left(2-\tau^{U}\right), \delta=-1 / \log _{2}\left(\tau^{L}\right)$ and $\tau^{U} \in[0,1], \tau^{L} \in[0,1]$. A key limitation of the JoeClayton copula is that there is some level of asymmetry due to its functional form, even though the two tail dependence measures are equal. In order to overcome this limitation, we use MJC which is characterized as:

$C_{M J C}\left(u, v \mid \tau^{U}, \tau^{L}\right)=\frac{1}{2} \times\left(C_{J C}\left(u, v \mid \tau^{U}, \tau^{L}\right)+C_{J C}\left(1-u, 1-v \mid \tau^{U}, \tau^{L}\right)+u+v-1\right)$

The above modification of the Joe-Clayton copula ensures that the tail dependence is not asymmetric when $\tau^{U}=\tau^{L}$. Next, we discuss the copula model specifications.

\subsubsection{Copula Model Specifications}

It is well established that financial returns generally do not follow a normal distribution but rather adhere to Student's t-distribution (Hu, 2010). Building on this, we model each marginal distribution of the asset returns employing an Autoregressive Moving Average ARMA (p, q)Exponential Generalized Autoregressive Conditional Heteroskedastic EGARCH $(1,1)$-t model to accommodate for differential impacts in return volatility clustering. Then, we estimate the scalefree measure of dependence, which preserves the dependence structure during the simulation of the RV.

Marginal Model: We assume that the distributions of the equity returns follow an ARMA (p, q)EGARCH $(1,1)$-t process (Nelson 1991). The model is characterized as

$$
\begin{gathered}
X_{i, t}=\theta_{i}+\sum_{j=1}^{p} \beta_{j} X_{i, t-j}+\sum_{k=1}^{q} \alpha_{k} \varepsilon_{i, t-k}+\varepsilon_{i, t} \\
\log \left(\sigma_{t}^{2}\right)=a_{0}+\sum_{j=1}^{p} a_{1 j} \log \left(\sigma_{t-j}^{2}\right)+\sum_{i=1}^{q} a_{2 i}\left|\frac{\varepsilon_{t-i}}{\sigma_{t-i}}\right|+\sum_{j=1}^{q} a_{3 j}\left(\frac{\varepsilon_{t-j}}{\sigma_{t-j}}\right) \\
\sqrt{\frac{d}{\sigma_{i, t}^{2}(d-2)}} \cdot \varepsilon_{i . t} \mid I_{t-1} \sim \text { i.i.d. } t_{d i}
\end{gathered}
$$


where $X_{i, t}$ is the asset return series, $\theta_{i}$ and $\varepsilon_{i, t-1}$ are the conditional mean and error term, which is the news relating to the volatility from one lag period. $\beta_{j}$ is the autoregressive component and $\alpha_{k}$ is the moving average parameter. The noise process $\varepsilon_{t}$ represented in Equation 4 follows a skewed Student's-t distribution with $(d)$ degrees of freedom and $\left(\sigma_{t}^{2}\right)$ conditional variance. $\left(\sigma_{t-j}^{2}\right)$ is the GARCH component and the leverage effect is captured by $a_{3}$. The information contained about the volatility of the lagged period is captured by $\varepsilon_{t-1}$ which represents the ARCH component. The information set is considered as the condition vector ' $k$ '. The order of the ARMA term ' $p$ ' is determined using Akaike Information Criteria (AIC).

In our study, we estimate ARMA (p, q) - EGARCH $(1,1)$ model for each of the financial return time-series. We select the most appropriate lag orders for each of the return series using the AIC, observing the conditional variance equation as an $\mathrm{EGARCH}(1,1)$-t process. The mean equations of the equity returns of India, US, UK, Germany, France, Canada and Japan follow ARMA (1, 1), $\operatorname{ARMA}(3,3), \operatorname{ARMA}(4,4), \operatorname{ARMA}(1,1), \operatorname{ARMA}(1,1), \operatorname{ARMA}(1,1)$ and $\operatorname{ARMA}(3,3)$ processes, respectively. We confirm that the marginal models are free from autocorrelation and heteroskedastic effects (results are not reported here but can be provided on request). To evaluate the adequacy of the marginal estimations, we conduct misspecification tests following Diebold et al. (1998). We examine the correlograms of $\left(\widehat{u_{t}}-\bar{u}\right)^{l}$ and $\left(\widehat{v_{t}}-\bar{v}\right)^{l}$ for ' 1 ' ranging from one to four. The values $\mathrm{u}$ and $\mathrm{v}$ are the probability integral transformations of the estimates of the marginal models. The correlograms confirm the absence of any serial correlation in the first four moments, which indicates that our marginal models are correctly specified.

Tail Dependence Measure: The tail dependence measure is another property of the copula that is very useful in analyzing the joint tail dependence of bivariate distributions. Tail dependence estimates the probability of the RV in lower or upper joint tails. Intuitively, this measures the tendency of the asset returns to co-move up and down together.

$$
\begin{gathered}
\tau^{U}=L t_{u \rightarrow 1} P\left[X \geq F_{X}^{-1}(u) / Y \geq F_{Y}^{-1}(u)\right]=L t_{u \rightarrow 1} \frac{1-2 u+C(u, u)}{1-u} \\
\tau^{L}=L t_{L \rightarrow O} P\left[X \geq F_{X}^{-1}(u) / Y \geq F_{Y}^{-1}(u)\right]=L t_{L \rightarrow 0} \frac{C(u, u)}{1-u}
\end{gathered}
$$


where $\tau^{U}, \tau^{L} \in[0,1]$ and $F_{X}^{-1}$ and $F_{Y}^{-1}$ are the marginal density functions of the RV series. If the tail dependence measures are positive then upper or lower tail dependence exists, i.e. $\tau^{U}\left(\tau^{L}\right)$ measures the probability of the RV-X being above (below) a high (low) quantile, given that the RV-Y is above (below) a high (low) quantile.

We allow for the tail dependence estimate to follow an evolution process that captures the level changes. We define the evolution process as

$$
\tau_{t}^{U / L}=\Theta\left(\beta_{0}^{U / L}+\beta_{1}^{U / L} \tau_{t-1}^{U / L}+\beta_{2}^{U / L} \frac{1}{q} \sum_{i=1}^{q}\left|u_{t-i}-v_{t-i}\right|+\beta_{3}^{U / L} D\right)
$$

where $\Theta=\frac{1}{1+e^{-x}}$ is a logistic transformation that is used to keep $\tau_{t}^{U / L}$ in $[0,1]$ at all times. The dependence parameter follows an $\operatorname{ARMA}(1, \mathrm{q})$ process, characterized by $\beta_{1}$, the autoregressive term, and $\beta_{2}$, the forcing variable. While the former term accounts for the persistence effect, the latter term captures the variation effect of the dependence parameter. We add a dummy variable term $\beta_{3} D$ to allow for level variation in the dependence. The dummy variable takes the value ' 0 ' for economic expansion regime and ' 1 ' otherwise. We obtain the dependence parameter of the Student-t and MJC copula models using the maximum likelihood (ML) method (see the estimation process in Appendix A).

We examine the performance of the copula models based on AIC, and Bayesian information criteria (BIC). The former is adjusted for small sample bias (Rodriguez 2007) and the latter is a goodness-of-fit test for the copula models to compare the different dependence structures.

\section{Empirical Results}

\subsection{Data Description}

We use S\&P GSCI Gold index (G), Standard and Poor's (S\&P) 500 index (E), US 10 year Government bond return index (B), West Texas Instrument - WTI crushing crude oil spot prices per barrel (O) and S\&P Case-Shiller Composite-10 home price index (RE). We estimate the dependence structures of four bivariate-asset pairs between gold and other assets by using time- 
varying conditional copula model. We calculate monthly returns to calibrate the ex-post quarterly dependence structure from the fourth quarter of 1987 to the fourth quarter of 2012.

\section{$<<$ Insert Table 1 >>}

Table 1 presents the summary statistics of the asset returns. Panel (A) of Table 1 shows that the annualized mean return of oil is the highest (6.33) than any other assets followed by equity and bond returns of 6.27 and 5.52 percent, respectively. The standard deviation of returns too is the highest for oil (33 percent) followed by equity (16.42 percent). Except for gold, returns of the other assets are negatively skewed. Returns for all assets show excess kurtosis, indicating that their distributions have a fatter tail and the probability of extreme variances is highly likely. The Jarque-Bera test statistics in Panel (B) of Table 1 confirm that the unconditional distributions of the asset returns are not normal. The Lagrangian Multiplier (LM) test to examine the presence of serial correlation of the squared return up to ten lags, confirms the presence of ARCH effects. Autocorrelation tests with correction for heteroskedasticity for lag orders 1, 5 and 10 confirm the presence of volatility clustering.

Panel (C) of Table 1 presents the mean and the standard deviation of the return comovements for the various asset pairs. The comovements for all asset pairs are positive except for equity-gold (0.047) and real estate-gold (-0.091) which suggests that gold returns are negatively correlated to the returns from equity and real estate. The average comovements is highest for the gold-oil pair (0.18) followed by equity-bond (0.11). The summary statistics show excess skewness and kurtosis which suggests that the distributions of return comovements have fatter tails and thus extreme variance is highly probable.

For using copula to examine the bivariate distributions, we first estimate the univariate marginal distribution of each asset returns. We use $\operatorname{ARMA}(p, q)-\operatorname{EGARCH}(1,1)$ model for each return series. We select the most appropriate lag order for each return series using the Akaike information criteria (AIC). The mean equations of equity, bond, real estate, gold and oil follow $\operatorname{ARMA}(2,2), \operatorname{ARMA}(5,5), \operatorname{ARMA}(7,7), \operatorname{ARMA}(6,6)$ and $\operatorname{ARMA}(7,6)$, respectively. We confirm that the marginal models are free from autocorrelation and heteroskedastic effects. 
Further, to evaluate the adequacy of the marginal models, we conduct misspecification tests following Diebold et al. (1998). We examine the correlograms of $\left(\hat{u}_{t}-\bar{u}\right)^{l}$ and $\left(\hat{v}_{t}-\bar{v}\right)^{l}$ for ' 1 ' ranging from one to four. The values $u$ and $v$ are the probability integral transformations of the estimates of the marginal models. The correlograms confirm absence of any serial correlation in the first four moments, which indicates that our marginal models returns are correctly specified. We do not report results here but these can be provided on request.

For examining the determinants of return comovements, we include four macroeconomic variables, i.e. the risk free rate $(r f)$, output gap $(o)$, inflation $(i)$, and risk aversion $(r a)$ and eight non-macroeconomic variables, i.e. output uncertainty (ou), inflation uncertainty (iu), gold market illiquidity $\left(g i l r_{t}\right)$, bond market illiquidity $(d s)$, equity market illiquidity $(l r)$, variance premium $(v p)$, term spread $(t s)$ and the depth of recession $(d r)$. Next, we discuss each of these state variables and examine their regime switching behaviour.

\subsection{Dependence Structure Dynamics}

We begin by determining whether there is evidence of regime switching behavior for each of the various dependence structures of gold return comovements. Panel C of Table 2 shows the transition probabilities and the expected durations ${ }^{1}$ of the regimes. The findings indicate significant transition probabilities for both the regimes, i.e. the dependence structure expansion phase (Regime 1) and the dependence structure contraction phase (Regime 2). The two regimes are identified using the Regime Classification Statistic (RCS).

The transition probability and the expected duration values presented in Panel C of Table 2 show that the dependence structure (DS) contraction regime tends to be considerably longer than the expansion regime. This suggests that investment in gold offers considerable diversification as the DS tends to stay in its lower state. This is further supported by low standard deviation observed for the expansion regime. However for the gold-bond and gold-oil pairs, we find higher standard deviations in the expansion regime. The key implication of these results is that the dependence

\footnotetext{
${ }^{1}$ Following Hamilton's (1989) formula we estimate the expected duration of the regimes as $\sum_{i=0}^{\infty} i p_{11(22)}^{i-1}(1-$ $p_{11(22)}$ ), where $p_{11(22)}$ are the transition probabilities in Regime 1 (Regime 2).
} 
structure increases faster than it decreases for these pairs which suggest volatility concordance for the gold-bond and gold-oil returns.

Figure 1 presents the time path of the dependence structures of the return comovements. It also shows the lower and the upper tails of the dependence structures. For all pairs, the dependence structures significantly differ from white noise and reveal useful information. For gold-bond and gold-oil pairs, we find that the dependence measure of lower tail is higher than the upper tail. This suggests that there is higher probability that these asset pairs will be affected by extreme events during the bear market than during the bull market. Further, the lower tails for these pairs show several peaks during the economic crisis periods, with the highest ones observed during the recent sub-prime led crisis. For other pairs, there is no evidence of tail dependence and hence extreme events are less likely to affect the gold-equity and gold-real estate asset pairs. This indicates that gold returns are not significantly affected by the extreme downturns or upturns in the stock and real estate markets. The results suggest that gold is a good hedge for stock and real estate based portfolios, especially during contractionary periods.

For the gold-equity pair, we find evidence of negative dependence during both phases of the economy. The average dependence measure is -0.046 and -0.047 during economic contraction and expansion phases, respectively. This suggests that investment in gold can provide a good hedge for equity-based portfolios. For the gold-real estate pair too, the average dependence measure is -0.091. In contrast, for gold-bond pair we observe positive a higher average dependence of 0.044 in the contraction phase compared with 0.027 for the expansion phase. The significant lower tail dependence for the gold-bond pair suggests a high probability of extreme gold-bond return comovements during the bear market. Likewise, the gold-oil return comovements is also positive (0.18) in the lower tail which suggests that the gold and oil returns have a high probability of extreme comovements in the crisis period. Consequently, gold may not be a good hedge for oil-based portfolios. Overall, we find evidence of return concordance between gold-bond and gold-oil during periods of economic contraction. The dependence structures of the return comovements vary significantly across the different asset pairs. This suggests that macroeconomic and non-macro factors affect the different return comovements differently. Thus understanding of the effects of economic and non-macroeconomic factors on 
the comovements of asset return dynamics is highly valuable for the strategic asset allocation. We examine the factor exposures of asset return comovements in the next section.

$$
\begin{aligned}
& <<\text { Insert Table 2>> } \\
& <<\text { Insert Figure 3>> }
\end{aligned}
$$

\subsection{Factor Exposure}

The factor exposures of the macro and the non-macro variables for the dependence structure expansion state (Regime 1) and for the dependence structure contraction state (Regime 2) are reported in Panels A and B of Table 2. It is interesting to observe that the factor exposures are not only different for the various dependence structures but they are also varying across the regimes. Thus, the MSSV model is appropriate for capturing the time-vary dynamics of the sources of return comovements.

We first focus on the macro economic variables (Panel A of Table 2). Interest rate negatively affects the gold-equity (G/E) dependence structure however its impact on gold-real estate (G/RE) and gold-oil (G/O) is positive. In other words when IR increases, the return comovements of these pairs also increase, which implies that rise in interest rates, has a positive impact on goldoil and gold-real estate return comovements. This suggests that gold is inappropriate in hedging against interest rate changes for real-estate and oil-based portfolios. Inflation has a positive influence on return comovements during the economic contraction phase except for G/RE. This indicates that gold is a good hedge against inflation for real-estate based investments. Output gap (O) has a negative coefficient indicating that positive output gap shocks have an inverse effect on the return comovements. Finally, we show that as investors become more risk averse, the return comovements across gold and other assets increase.

The effects of the non-macroeconomic variables are presented in Panel B of Table 2. We find that uncertainty parameters and the illiquidity variables play a more prominent role in influencing the return comovements. Output uncertainty positively affects the dependence structure of $\mathrm{G} / \mathrm{B}$ during both the economic phases and of $\mathrm{G} / \mathrm{O}$ during the contraction regime. In contrast, inflation uncertainty (IU) bears a negative sign and shows considerable explanatory power. The findings show that for bond portfolios, gold makes a good hedge against inflation uncertainty. The positive impact of IU on gold-equity is potentially consistent with the learning 
models of Veronesi (1999), in which the uncertainty decreases the equity risk premium. Most intriguing is the negative significance of $\mathrm{IU}$ on $\mathrm{G} / \mathrm{O}$ which indicates a possibly negative relationship between the interest rates and inflation uncertainty consistent with the findings of Juster and Taylor (1975). Further, Cukierman and Meltzer (1986) argue that unanticipated inflation can be generated in order to stimulate economies by reducing the interest rates. Concerning the liquidity factors, while stock illiquidity negatively affects the DSs during the expansion phases, it has a positive impact on the G/E pair during the economic contraction phase. The former suggests that economic recovery drives investors and traders from less liquid gold into highly liquid and riskier assets like equities and the resulting price-pressure leads to negative return comovements. The highly significant negative impact of gold liquidity (GLIR) on $\mathrm{G} / \mathrm{E}$ during the economic contraction phase is potentially consistent with the findings of Baur and Lucey (2010) and Baur and McDermott (2010), suggesting that gold acts as a safe-haven investment in volatile market conditions. The positive of impact of GLIR on G/B during the economic expansion phase indicates that increase in demand for gold during contraction period triggers increase in bond investments. In contrast the negative impact of bond illiquidity during either of the phases suggests that decrease in demand for bond indicates a rise in gold investments.

Finally, variance premium negatively impacts the return comovements in both regimes, especially for the G/E pair. The variance premium measure allows us to capture the non-linearity in the consumption growth technology, which depends positively on implied volatility of stock returns but negatively on observed volatility. Thus, it allows us to establish whether the "flightto-safety" effect is due to the risk-premium component of the implied volatility, or due to general stock market uncertainty. Since, variance premium is high in recession; a negative coefficient suggests that the observed "flight to safety" phenomenon in the gold and equity market is due to the implied volatility of the stock market.

\subsection{Factor Contributions}

Next we investigate to what extent the macro and non-macroeconomic factors contribute to the model fit in explaining the asset return comovements of different asset pairs. Table 3 reports the results. Based on the information criteria, i.e. AIC and BIC, the findings indicate that the model 
fit worsens considerably when the non-macro factors are dropped for all the pairs except for the gold-real estate pair. In particular among the non-macro factors, uncertainty, illiquidity and variance premium contribute significantly in explaining the variations of the dependence structure. Among the macroeconomic variables, the interest rate, inflation and risk aversion play a dominant role. In particular, we note that inflation uncertainty has considerable explanatory powers. Overall, our findings indicate that non-macro factors contribute significantly in explaining the dynamics of the asymmetric dependence structure of gold and other asset return comovements.

$<<$ Insert Table 3>> 


\subsection{Forecasting performance of asset return comovements}

Table 4 presents the median of squared errors and the coefficients of the forecast efficiency regression for the MSSV and the non-regime switching models. The results are reported for the rolling forecasting for both the sub-samples. It is evident that for the MSSV model, the median of squared errors are significantly lower and the null hypotheses of $\alpha=0$ and $\beta=1$ cannot be rejected. This indicates that the MSSV model adequately captures the dynamics of the asset return comovements.

In contrast the null hypotheses of $\alpha=0$ and $\beta=1$, can be significantly rejected for the NRS models. This suggests that the non-regime switching models are effective in capturing the extreme return comovements. The findings of $\alpha \neq 0$ and $\beta \neq 1$ indicate that the non-regime switching model either underestimates or overestimates the true volatility of asset return comovements. To distinguish between the two cases, i.e. high and low volatility of return comovements, we re-estimate the forecast efficiency by allowing a break in the regression line at the median forecast. Thus, we estimate two pairs of $(\alpha, \beta)$ coefficients. One pair, $\left(\alpha^{+}, \beta^{+}\right)$for forecasts above the median and another pair, $\left(\alpha^{-}, \beta^{-}\right)$for forecasts below the median. The results are presented in the Table 5. The findings indicate that $\left(\alpha^{+}, \beta^{+}\right)$are significantly different from $(0,1)$. The estimated coefficients of $\beta^{+}$indicates that non-regime models overestimate the true variance. These observations are similar for both samples.

These findings imply that the MSSV framework captures the persistence in volatility shocks. For instance, if shocks are more persistent in periods of economic contraction than in periods of economic recovery, this is effectively captured by the regime parameters. Moreover, our Markov switching model is able to capture the 'pressure smoothening' effects of those shocks that are not persistent and are followed by low volatility regimes.

$<<$ Insert Table 4>>

$<<$ Insert Table 5>>

\subsection{Economic Value of Asset Return Comovements}

Knowledge of the variables that drive the asset return comovements will be useful for investors in improving their asset allocation decisions. In this subsection, we examine whether this is true 
for a short-horizon dynamic strategy. In short-horizon dynamic strategy investors seek to maximize their one-period utility and do not hedge against future changes in the investment opportunity set (Fleming et al., 2001). Since short-horizon dynamic strategy ignores the hedging component, it is expected to underperform the optimal strategy under Merton's (1973) framework. Therefore, compared to an optimal strategy, a short-horizon strategy sets a higher bar for significant economic value added.

Fleming et al.'s (2001) framework does not allow an analytical solution for the optimal portfolio. Therefore, they evaluate their short-horizon dynamic strategy by examining two sub-optimal portfolios relating to maximum-mean and minimum-variance. To overcome this issue, we assume a power utility function over terminal wealth, i.e. $U\left(W_{T}\right)=W_{T}^{1-\gamma} /(1-\gamma)$, where $\gamma$ is the risk aversion coefficient of the utility function. Based on Campbell and Viceira (2002), oneperiod optimal asset allocation is defined as

$$
A_{t}^{w}=\frac{1}{\gamma} \Sigma_{t}^{-1}\left(E_{t} r_{t+1}-R f_{t} . I-\sigma_{t}^{2} / 2\right)
$$

where $A_{t}^{w}$ is the vector of asset weights, $\Sigma_{t}$ is the conditional asset return covariance matrix, $E_{t} r_{t+1}$ is the expected asset return vector, $R f_{t}$ is the risk-free rate, $I=[1,1]^{\prime}$ and $\sigma_{t}^{2}$ is the vector of asset variances.

Below, we present a comparison of two strategies: a multivariate conditional covariance (MCC) strategy and a dynamic strategy. In the MCC strategy, investors employ the multivariate conditional covariance using diagonal BEKK model for forecasting one-period ahead return comovements and in the dynamic strategy, the investors base their forecast on the macroeconomic and the non-macroeconomic variables. The investors form their portfolio based on Equation (14) and rebalance them at the end of each quarter. The portfolio formation period is 1987 to 2002 and the investment period is from 2003 to 2012. The portfolio includes gold, equities, bond, real estate and oil.

We use Willing-to-Pay (WTP) as a measure of certainty equivalence to evaluate the economic value. WTP is defined as the maximum fee $(f)$ an investor is willing to pay for holding a dynamic strategy over the other strategy. WTP is defined as: 


$$
W T P=\sup \left\{f \mid E\left(U\left(W^{E M A / M C C}\right)\right) \leq E\left(U\left(W^{\text {dynamic }}-f\right)\right)\right\}
$$

Considering terminal wealth $W_{T}=W_{i} \prod_{t=1}^{T}\left(1+r_{t}\right)$, where $W_{i}$ is investor's initial wealth, expected log-utility is defined using

$$
\begin{aligned}
W \log \left(U\left(W_{T}\right)\right) & =(1-\gamma) \sum_{t=1}^{T} \log \left(1+r_{t}\right)+(1-\gamma) \log W_{i}-\log (1-\gamma) \\
& =(1+\gamma) T \cdot \overline{\log \left(1+r_{t}\right)}+(1-\gamma) \log W_{i}-\log (1-\gamma)
\end{aligned}
$$

The above equation suggests that $U\left(W_{T}\right)$ is log normally distributed. Therefore, expected utility is computed as

$$
\begin{aligned}
\overline{U\left(W_{T}\right)}=\exp ( & (1+\gamma) T \cdot \overline{\log \left(1+r_{t}\right)} \\
& \left.+\frac{1}{2}(1-\gamma)^{2} T^{2} \widehat{\operatorname{Var}}\left(\overline{\log \left(1+r_{t}\right)}\right)\right) \cdot \frac{W_{i}^{1-\gamma}}{1-\gamma}
\end{aligned}
$$

Table 6 compares the performance of the two strategies for various levels of risk aversion and the-risk free rate. The last column reports the bootstrapped p-values of the hypothesis: $H_{\text {null }}: W T P \leq 0$. The main findings are as follows. First, for constant relative risk aversion investors, the dynamic strategy outperforms the MCC strategy, i.e. for all instances the hypothesis $W T P \leq 0$ is rejected. Second, the findings show that the dynamic strategy is more risky. In other words the mean and the volatility are higher for the dynamic strategy. However, the Sharpe ratios indicate that in the dynamic strategy, investors are better rewarded. Third, the WTP decreases with increase in risk aversion $(\gamma)$. This suggests that higher risk aversion discourages investors in holding riskier assets, thus making it difficult to differentiate between either of the strategies. Fourth, the WTP increases with increase in risk-free rate. This is because, the dynamic strategy investors are more informed in taking advantage of the diversification opportunities arising from the influence of risk-free rate on the asset return comovements.

Overall, the findings reported in Table 6 indicate that the dynamic strategy outperforms the MCC strategy. The findings imply that both understanding the dynamics and the influence of 
macroeconomic and non-macroeconomic variables on asset return comovements enhances investor's optimal portfolio choices.

\author{
$<<$ Insert Table 6>>
}

\title{
4. Conclusions
}

Considerable time variation in the asset return comovements has been of key interest to portfolio managers and academic researchers. Much of the research in this area has been restricted to the conventional financial assets, i.e. stocks and bonds. In particular, despite the importance of gold as a hedge commodity and a safe haven, studies investigating the dependence structure of gold returns and other assets are rare. Further, there is little research on the impact of changes in the real economy and non-macro factors on the dynamics of return comovements of gold and other financial assets. Also, the extant research has examined the asset return comovements by using linear correlation as a measure of comovements. However, it is well documented in the literature that linear correlation fails to provide an accurate estimate of the dependence structure when dealing with multivariate distributions with complex dynamic characteristics (Chan, et al., 2011; Reboredo, 2011). Under such circumstances, the copula technique that we employ enables us to examine return comovements during the extremes.

Using data from 1987 to 2012 for gold and three different asset classes and several macro and non-macro variables, we report a number of significant findings. First, we confirm that the dependence structures of gold and other asset return comovements show significant regimeswitching behavior both in terms of statistical and economic significance, which corresponds to periods of economic expansion and economic contraction. Importantly, the transition probabilities of the different regimes indicate that investment in gold leads to risk diversification. Second, examining the factor contributions, we find that the model fit worsens considerably when the non-macro factors are dropped for all the pairs except for gold-real estate dependence structure. This signifies the importance of considering the impact of economic uncertainty on financial markets prior to asset allocation for portfolio diversification. Third, we show that that rise in interest rates, has a positive impact on gold-oil and real-estate return comovements. This suggests that gold is an inappropriate hedge against interest rate changes for real estate and oilbased portfolios. Fourth, we find that inflation positively impacts the return comovements of all 
the asset pairs except for gold and real estate. This implies that gold is a good hedge against inflation for real-estate based investments. Fifth, amongst the non-macro variables we find that uncertainty parameters and the illiquidity variables are more prominent. In particular, we show that for bond portfolios, gold makes a good hedge against inflation uncertainty. Sixth, consistent with previous literature we find evidence to suggest that gold acts as a safe-haven investment, particularly in volatile stock market conditions. Further, we reveal that during the economic contraction phase increase in demand for gold potentially triggers increase in bond investments. In contrast, the negative impact of bond illiquidity during either of the phases suggests that decrease in demand for bond indicates a rise in gold investments. Seventh, our findings suggest that the observed "flight to safety" phenomenon in the gold and equity market is due to the implied volatility of the stock market, rather than the observed stock market uncertainty. Finally, we show that increase in investors' risk aversion is associated with increase in the return comovements of gold and other assets.

The study also makes significant contributions to the extant literature on forecasting of return comovements. The evidence presented in the paper shows that the MSSV framework is effective in capturing the persistence in volatility shocks. Moreover, the model is able to capture the 'pressure smoothening' effects of those shocks that are not persistent. Overall, our research suggests that the dynamic strategy incorporating regime switching framework outperforms the multivariate conditional covariance strategy in forecasting multi-asset return comovements. Investors with different risk-appetites are able to enhance their portfolio optimisation choices by utilising the analytical approach proposed in the study. 


\section{References}

Amihud, Y. 2002. Illiquidity and stock returns: cross-section and time-series effects. Journal of Financial Markets 5, 31-56.

Ang, A., \& Bekaert, G. 2002. International asset allocation with regime shifts. Review of Financial Studies 15, 1137-1187.

Baele, L., Bekaert, G., \& Inghelbrecht, K. 2010. The determinants of stock and bond return comovements. Review of Financial Studies 23, 2374-2428.

Ball, C.A., Torous, W.N. 1999. The stochastic volatility of short-term interest rates: Some international evidence. J Financ 54, 2339-2359

Batten, J. A., \& Lucey, B. M. 2009. Volatility in the gold futures market. Applied Economics Letters 17, 187-190.

Baur, D. G. 2012. Asymmetric volatility in the gold market. The Journal of Alternative Investments 14, 26-38.

Baur, D. G., \& Lucey, B. M. 2010. Is gold a hedge or a safe haven? An analysis of stocks, bonds and gold. Financial Review 45, 217-229.

Baur, D. G., \& McDermott, T. K. 2010. Is gold a safe haven? International evidence. Journal of Banking \& Finance 34, 1886-1898.

Bekaert, G., Cho, S., \& Moreno, A. 2010. New Keynesian Macroeconomics and the Term Structure. Journal of Money, Credit and Banking 42, 33-62.

Bekaert, G., \& Engstrom, E. 2010. Inflation and the stock market: Understanding the 'Fed Model'. Journal of Monetary Economics 57, 278-294.

Bollerslev, T., Engle, R. F., \& Wooldridge, J. M. 1988. A capital asset pricing model with timevarying covariances. The Journal of Political Economy 96, 116-131.

Campbell, J. Y., \& Cochrane, J. H. 1995. By force of habit: A consumption-based explanation of aggregate stock market behavior. Journal of Political Economy 107, 205-211.

Campbell, J. Y., L.M. Viceira, 2002. Strategic asset allocation: portfolio choice for long-term investors. Oxford University Press, Oxford.

Cashin, P., McDermott, C. J., \& Scott, A. 2002. Booms and slumps in world commodity prices. Journal of Development Economics 69, 277-296. 
Chan, K. F., Treepongkaruna, S., Brooks, R., \& Gray, S. 2011. Asset market linkages: Evidence from financial, commodity and real estate assets. Journal of Banking \& Finance 35, $1415-$ 1426.

Cho, S., \& Moreno, A. 2006. A small-sample study of the New-Keynesian macro model. Journal of Money Credit and banking 38, 1461.

Chordia, T., Sarkar, A., \& Subrahmanyam, A. 2005. An empirical analysis of stock and bond market liquidity. Review of Financial Studies 18, 85-129.

Cukierman, A., \& Meltzer, A. H. 1986. A theory of ambiguity, credibility, and inflation under discretion and asymmetric information. Econometrica: Journal of the Econometric Society, 1099-1128.

d'Addona, S., A. H. Kind, 2006. International Stock-Bond correlations in a simple affine asset pricing model. Journal of Banking \& Finance 30, 2747-2765.

Diebold, F. X., Gunther, T. A., \& Tay, A. S. 1998. Evaluating density forecasts, with applications to financial riak management. International Economics Review 39, 863-883.

Dotsey, M. 1998. The predictive content of the interest rate term spread for future economic growth. Economic Quarterly-Federal Reserve Bank of Richmond 84, 31-52.

Engle, R. F. 1982. Autoregressive conditional heteroscedasticity with estimates of the variance of United Kingdom inflation. Econometrica: Journal of the Econometric Society 50, 9871007.

Estrella, A., \& Hardouvelis, G. A. 2012. The term structure as a predictor of real economic activity. The Journal of Finance 46, 555-576.

Fleming, J., C. Kirby, B. Ostdiek, 2001. The economic value of volatility timing. The Journal of Finance 56, 329-352.

Furlong, F., \& Ingenito, R. 1996. Commodity prices and inflation. Economic Review-Federal Reserve Bank of San Francisco, 27-47.

Goyenko, R. Y., Holden, C. W., \& Trzcinka, C. A. 2009. Do liquidity measures measure liquidity? Journal of Financial Economics 92, 153-181.

Guidolin, M., \& Timmermann, A. 2007. Asset allocation under multivariate regime switching. Journal of Economic Dynamics and Control 31, 3503-3544.

Hamilton, J. D. 1989. A new approach to the economic analysis of nonstationary time series and the business cycle. Econometrica 57, 357-384. 
Hasbrouck, J. 2009. Trading costs and returns for US equities: Estimating effective costs from daily data. The Journal of Finance 64, 1445-1477.

Henry, O. T., Olekalns, N., \& Thong, J. 2004. Do stock market returns predict changes to output? Evidence from a nonlinear panel data model. Empirical Economics 29, 527-540.

Hooker, M. A. 2002. Are oil shocks inflationary?: Asymmetric and nonlinear specifications versus changes in regime. Journal of Money, Credit, and Banking 34, 540-561.

$\mathrm{Hu}$, J. 2010. Dependence structures in Chinese and US financial markets: a time-varying conditional copula approach. Applied Financ Econ 20, 561-583

Hunt, B. 2006. Oil price shocks and the US stagflation of the 1970s: some Insights from GEM. The Energy Journal, 61-80.

Jondeau, E., \& Rockinger, M. 2006. The copula-garch model of conditional dependencies: An international stock market application. Journal of International Money and Finance 25, 827-853.

Juster, F. T., \& Taylor, L. D. 1975. Towards a theory of saving behavior. The American Economic Review, 203-209.

Kim, C. J. 1994. Dynamic linear models with Markov-switching. Journal of Econometrics 60, 1 22.

Lee, Y. M., \& Wang, K. M. 2012. Searching for a better proxy for business cycles: with supports using US data. Applied Economics 44, 1433-1442.

Merton, R. C. 1973. An intertemporal capital asset pricing model. Econometrica: Journal of the Econometric Society, 867-887.

NBER. 2013, NBER.

Nelson, D. B. 1991. Conditional heteroskedasticity in asset returns: A new approach. Econometrica: Journal of the Econometric Society 59, 347-370.

Newey, W. K., K.D. West, 1987. Hypothesis testing with efficient method of moments estimation. International Economic Review, 777-787.

Öcal, N. 2006. Nonlinear models, composite longer leading indicator and forecasts for UK real GDP. Applied Economics 38, 1049-1053.

Pagan, A. R., G.W. Schwert, 1990. Alternative models for conditional stock volatility. Journal of econometrics 45, 267-290. 
Pindyck, R. S., \& Rotemberg, J. J. 1990. The excess co-movement of commodity prices. Economic Journal 100, 1173-1189.

Piplack, J., \& Straetmans, S. 2010. Comovements of Different Asset Classes during Market Stress. Pacific Economic Review 15, 385-400.

Plosser, C. I., \& Geert Rouwenhorst, K. 1994. International term structures and real economic growth. Journal of Monetary Economics 33, 133-155.

Reboredo, J. C. 2011. How do crude oil prices co-move?: A copula approach. Energy Economics $33,948-955$.

Rodriguez, J.C. 2007. Measuring financial contagion: A copula approach, J Empir Financ 14, 401-423

Shephard, N. 1996. Statistical aspects of ARCH and stochastic volatility. MG Stat Pro 65, 1-68.

Šimáková, J. 2011. Analysis of the Relationship between Oil and Gold Prices. Journal of Finance $51,651-662$.

Sklar, A. 1959. Fonctions de répartition à n dimensions et leurs marges", Publ. Inst. Statist. Univ. Paris 8, 11 .

Smith, D. R. 2002. Markov-switching and stochastic volatility diffusion models of short-term interest rates. Journal of Business \& Economic Statistics 20, 183-197.

Tully, E., \& Lucey, B. M. 2007. A power GARCH examination of the gold market. Research in International Business and Finance 21, 316-325.

Veronesi, P. 1999. Stock market overreactions to bad news in good times: a rational expectations equilibrium model. Review of Financial Studies 12, 975-1007.

West, K.D., M.W. McCracken, 1998. Regression-Based Tests of Predictive Ability. International Economic Review 39, 817-840. 
Table 1: Summary Statistics

\begin{tabular}{lccccc}
\hline Panel A: Descriptive Statistics of Asset Returns (1987 - 2012) & & & & \\
& Equity (E) & Bond (B) & Real Estate (RE) & Gold (G) & Oil (O) \\
\hline Mean (\%) & 6.274 & 5.524 & 3.394 & 5.438 & 6.331 \\
Standard Deviation (\%) & 16.428 & 1.293 & 2.730 & 15.449 & 33.000 \\
Kurtosis & 3.854 & 0.138 & 0.611 & 1.986 & 1.687 \\
Skewness & -1.114 & -0.165 & -0.726 & 0.064 & -0.357 \\
\hline Panel B: Diagnostics (1987-2012) & & & & \\
& Equity (E) & Bond (B) & Real Estate (RE) & Gold (G) & Oil (O) \\
\hline Jarque-Bera statistics & $208.3^{* *}$ & $7.7^{* *}$ & $31.5 * *$ & $45.7^{* *}$ & $48.4^{* *}$ \\
& $(0.000)$ & $(0.020)$ & $(0.000)$ & $(0.000)$ & $(0.000)$ \\
ARCH LM statistic (1) & $31.586^{* *}$ & $17.737^{* *}$ & $1741.764^{* *}$ & $4.586^{* *}$ & $13.676^{* *}$ \\
ARCH LM statistic (5) & $(0.000)$ & $(0.000)$ & $(0.000)$ & $(0.033)$ & $(0.000)$ \\
& $17.489 * *$ & $8.571^{* *}$ & $371.920^{* *}$ & $3.003^{* *}$ & $4.563^{* *}$ \\
ARCH LM statistic (10) & $(0.000)$ & $(0.000)$ & $(0.000)$ & $(0.016)$ & $(0.000)$ \\
& $12.804^{* *}$ & $4.903^{* *}$ & $190.231^{* *}$ & $1.927^{* *}$ & $2.913^{* *}$ \\
Ljung-Box statistic (1) & $(0.000)$ & $(0.000)$ & $(0.000)$ & $(0.041)$ & $(0.001)$ \\
Ljung-Box statistic (5) & $9.293^{* *}$ & $9649.404^{* *}$ & $4232.160^{* *}$ & $4.433^{* *}$ & $5.757^{* *}$
\end{tabular}

\begin{tabular}{lccccc}
\hline Panel C: Descriptive Statistics of the Dependence Structures & & & & \\
& & & & \\
& Mean & Standard Error & Deviation & Kurtosis & Skewness \\
\hline Equity-Bond (EB) & 0.1131 & 0.0124 & 0.1250 & 5.2245 & 1.9484 \\
Equity-Real estate (ERe) & 0.0777 & 0.0072 & 0.0720 & -0.9398 & -0.0323 \\
Equity- Gold (EG) & -0.047 & 0.0037 & 0.0370 & -0.3393 & -0.0670 \\
Equity-Oil (EO) & 0.1048 & 0.0297 & 0.2980 & -0.1854 & 0.1111 \\
Bond-Real estate (BRe) & 0.1125 & 0.0048 & 0.0487 & -0.1293 & -0.3535 \\
Bond-Gold (BG) & 0.0286 & 0.0072 & 0.0726 & 4.1310 & -0.8807 \\
Bond-Oil (BO) & 0.0168 & 0.0007 & 0.0074 & 5.3784 & -1.7145 \\
Real estate-Gold (ReG) & -0.091 & 0.0035 & 0.0356 & 1.0910 & 1.0125 \\
Real estate-Oil (ReO) & 0.0046 & 0.0044 & 0.0437 & 1.8548 & 0.3699 \\
Gold-Oil (GO) & 0.1802 & 0.0166 & 0.1672 & -0.3301 & -0.2617 \\
\hline
\end{tabular}


Note: Panel A represents the descriptive statistics of the asset returns. The sample period is from the fourth quarter of 1987 to the fourth quarter of 2012. The returns are annualized from the monthly observations. Annualized return $=\left[(1+\text { monthly mean return })^{12}-1\right]$, Annualized standard deviation $=$ [monthly standard deviation $\times 12^{1 / 2}$ ]. Panel B provides the diagnostic test results. Under the normality null hypothesis, Jarque-Bera test statistic follows a Chi-square distribution with fixed (2) degrees of freedom. The null hypothesis of the ARCH-LM test is: there is no evidence of ARCH effect. We conduct the test at lags 1, 5 and 10 with corresponding 1, 5, 10 degrees of freedom. Tests using other lags yield the same results. The Jarque-Bera test statistics in Panel (B) confirm that the unconditional distributions of the asset returns are not normal. We conduct the Ljung-Box test for serial correlation, corrected for heteroskedasticity at lags 1,5 and 10. The p-values are reported in the parentheses. The significant LM statistics confirm the presence of autoregressive conditional heteroskedastic (ARCH) effects. The LjungBox test also reports that most of the asset returns are serially correlated for at least one of the lag orders. Panel $\mathrm{C}$ reports the descriptive statistics of the dependence measures of the different asset pairs for the period 1987 to 2012: equity and bond (EB), equity and real estate (Ere), equity and gold (EG), equity and oil (EO), bond and real estate (BRe), bond and gold (BG), bond and oil (BO), real estate and gold (ReG), real estate and oil ( $\mathrm{ReO})$ and gold and oil (GO). The estimates of the copula parameters can be provided on request. The summary statistics show excess skewness and kurtosis which suggests that the distributions have a fatter tail and thus extreme variance is highly probable.

** signifies rejection of the null hypothesis at 5 percent level. 
Table 2: Summary of Significant Factor Exposure

\begin{tabular}{|c|c|c|c|c|c|c|}
\hline \multicolumn{7}{|c|}{ Panel A: Macroeconomic Factor exposure of Dependence Structures } \\
\hline & \multirow{2}{*}{$\begin{array}{c}\text { DS } \\
\text { Regimes }\end{array}$} & \multirow[b]{2}{*}{ Constant } & \multicolumn{4}{|c|}{ Macroeconomic Factors } \\
\hline & & & RF & $\mathrm{O}$ & I & RA \\
\hline \multirow{4}{*}{$\begin{array}{l}\text { Panel A } \\
\text { Gold- } \\
\text { Equity }\end{array}$} & Regime 1 & 0.021 & $-1.222 * * *$ & 0.061 & $0.161 * *$ & $1.173 * * *$ \\
\hline & (EC) & $(0.494)$ & $(0.000)$ & $(0.555)$ & $(0.028)$ & $(0.000)$ \\
\hline & Regime 2 & 0.018 & $-0.474 * *$ & $-0.270^{* * *}$ & 0.381 & 0.093 \\
\hline & (EE) & $(0.287)$ & $(0.047)$ & $(0.001)$ & $(0.052)$ & $(0.597)$ \\
\hline \multirow{4}{*}{$\begin{array}{l}\text { Panel B } \\
\text { Gold- } \\
\text { Bond }\end{array}$} & Regime 1 & $-0.088^{* * *}$ & 0.443 & $-1.270^{* * *}$ & $0.422 * *$ & -0.071 \\
\hline & $(\mathrm{EC})$ & $(0.000)$ & $(0.173)$ & $(0.000)$ & $(0.029)$ & $(0.782)$ \\
\hline & Regime 2 & 0.039 & -0.349 & -0.033 & -0.067 & $0.533^{* * *}$ \\
\hline & (EE) & $(0.417)$ & $(0.063)$ & $(0.573)$ & (0.299) & $(0.000)$ \\
\hline \multirow{4}{*}{$\begin{array}{c}\text { Panel C } \\
\text { Gold- } \\
\text { Real } \\
\text { Estate } \\
\text { Regime }\end{array}$} & Regime 1 & 0.180 & -0.493 & $0.443 * * *$ & $-0.322^{* *}$ & 0.216 \\
\hline & $(\mathrm{EC})$ & $(0.954)$ & $(0.297)$ & $(0.000)$ & $(0.012)$ & $(0.409)$ \\
\hline & Regime 2 & $0.019 * * *$ & $0.972 * * *$ & 0.134 & $0.479 * * *$ & -0.416 \\
\hline & (EE) & $(0.005)$ & $(0.005)$ & $(0.621)$ & $(0.008)$ & $(0.121)$ \\
\hline \multirow[t]{2}{*}{ Panel D } & Regime 1 & 1.004 & $0.729 * * *$ & -0.146 & -0.128 & $0.410^{* *}$ \\
\hline & $(\mathrm{EC})$ & $(0.762)$ & $(0.005)$ & $(0.186)$ & $(0.192)$ & $(0.034)$ \\
\hline \multirow[t]{2}{*}{ Gold-Oil } & Regime 2 & $0.036 * * *$ & $0.757 * *$ & $0.461^{*}$ & 0.028 & $0.683 * * *$ \\
\hline & (EE) & $(0.005)$ & $(0.040)$ & (0.094) & $(0.845)$ & $(0.000)$ \\
\hline
\end{tabular}


Panel B: Non-Macroeconomic Factor exposure of Dependence Structures

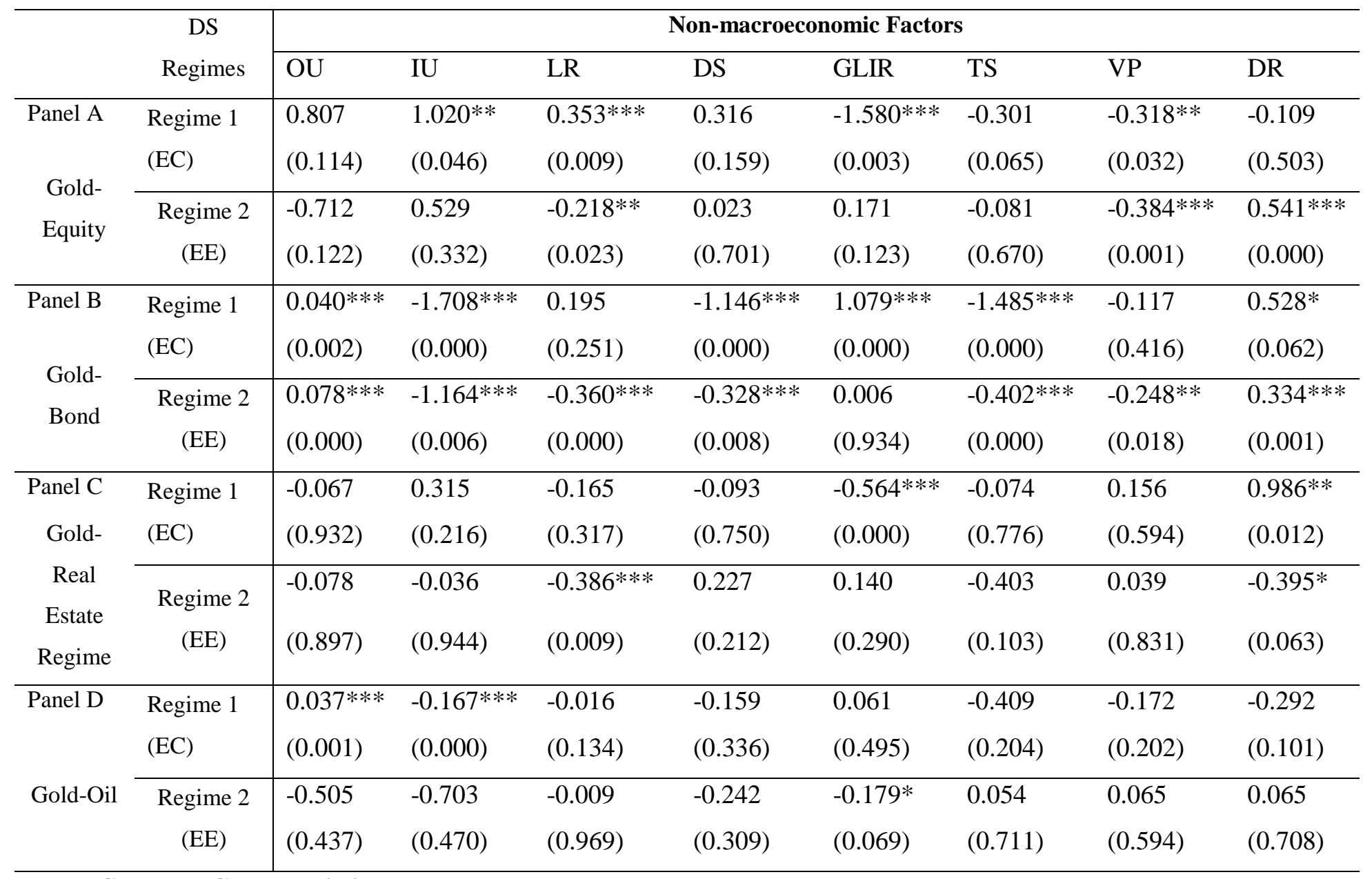

Panel C: Model Characteristics

\begin{tabular}{cc|ccc}
\hline & $\begin{array}{c}\text { DS } \\
\text { Regimes }\end{array}$ & SD & TP & Duration \\
\hline Panel A & Regime 1 & $0.021 * *$ & $0.68 * * *$ & 3.16 \\
\cline { 2 - 4 } & & &
\end{tabular}




\begin{tabular}{|c|c|c|c|c|}
\hline \multirow{2}{*}{$\begin{array}{l}\text { Gold- } \\
\text { Equity }\end{array}$} & (EC) & (0.041) & (0.018) & \\
\hline & $\begin{array}{c}\text { Regime } 2 \\
\text { (EE) }\end{array}$ & $\begin{array}{l}0.064 * * \\
(0.019)\end{array}$ & $\begin{array}{l}0.73 * * \\
(0.056)\end{array}$ & 3.68 \\
\hline Panel B & $\begin{array}{l}\text { Regime } 1 \\
\text { (EC) }\end{array}$ & $\begin{array}{c}0.067 \text { ** } \\
(0.037)\end{array}$ & $\begin{array}{l}0.45^{* *} \\
(0.037)\end{array}$ & 1.84 \\
\hline Bond & $\begin{array}{c}\text { Regime } 2 \\
\text { (EE) }\end{array}$ & $\begin{array}{l}0.021 * * \\
(0.027)\end{array}$ & $\begin{array}{l}0.81 * * \\
(0.029)\end{array}$ & 5.31 \\
\hline $\begin{array}{r}\text { Panel C } \\
\text { Gold- }\end{array}$ & $\begin{array}{l}\text { Regime } 1 \\
\text { (EC) }\end{array}$ & $\begin{array}{c}0.018^{* *} \\
(0.040)\end{array}$ & $\begin{array}{l}0.79 * * \\
(0.037)\end{array}$ & 4.94 \\
\hline $\begin{array}{c}\text { Real } \\
\text { Estate } \\
\text { Regime }\end{array}$ & $\begin{array}{c}\text { Regime } 2 \\
\text { (EE) }\end{array}$ & $\begin{array}{l}0.025^{* *} \\
(0.039)\end{array}$ & $\begin{array}{l}0.84^{* *} \\
(0.041)\end{array}$ & 6.42 \\
\hline Panel D & $\begin{array}{l}\text { Regime } 1 \\
\text { (EC) }\end{array}$ & $\begin{array}{c}0.65 * * * \\
(0.031)\end{array}$ & $\begin{array}{l}0.88 * * \\
(0.039)\end{array}$ & 8.58 \\
\hline Gold-Oil & $\begin{array}{c}\text { Regime } 2 \\
\text { (EE) }\end{array}$ & $\begin{array}{l}0.032 * * \\
(0.023)\end{array}$ & $\begin{array}{l}0.89 * * \\
(0.034)\end{array}$ & 9.31 \\
\hline
\end{tabular}

${ }^{\mathrm{a}}$ Note: The table reports the summary the parameter estimation results of the Markov switching stochastic volatility models of the twelve state variables for the various dependence structure of gold and other asset returns. Regime 1 corresponds to the expansion regime of the dependence measure and Regime 2 corresponds to the contraction regime of the dependence measure. The expansion regime of the dependence structure relates to economic contraction (EC) phase and the contraction regime of the dependence structure relates to economic expansion (EE) phase. In panel A we report the factor exposure of the macroeconomic variables. In the set of macroeconomic state variables RF is risk free rate, $\mathrm{O}$ is output gap, I is inflation and RA is risk aversion. In Panel B we report the factor exposure of the non-macroeconomic variables. In the set of non-macro factors OU is output uncertainty, IU inflation uncertainty, LR measure equity illiquidity, DS is bond illiquidity measure, GLIR is gold liquidity factor, TS is term spread, VP is variance premium and DR is depth of recession. In Panel C we report the model characteristics. SD reports the standard deviation of the regime states. TP corresponds to the transition probabilities of the two regimes. TP for Regime 1 refers to the probability of the dependence measure to stay in the expansion regime and TP for Regime 2 corresponds to the probability of the dependence measure to stay 
in contraction regime. The p-values are reported in parenthesis. Duration corresponds to the expected duration of the dependence measure in the expansion regime (Regime 1) and in the contraction regime (Regime 2). The sample period is from the fourth quarter 1987 to the fourth quarter 212.

** corresponds to 5 percent significance level and $* * *$ corresponds to one percent significance level. 
Table 3: Factor Contributions to Model Performance ${ }^{\text {a }}$

\begin{tabular}{lccc}
\hline Model Performance & Full Model & Minus non-Macro Factors & Minus Macro Factors \\
\hline Panel A: Gold-Equity Dependence Structure & \\
AIC & -391.583 & -220.013 & -253.836 \\
BIC & -355.241 & -213.402 & -201.534 \\
\hline Panel B: Gold-Bond Dependence Structure & -215.289 & -246.278 \\
AIC & -239.127 & -208.677 & -253.976 \\
BIC & -165.904 & & \\
\hline
\end{tabular}

Panel C: Gold-Real Estate Dependence Structure

$\begin{array}{llll}\text { AIC } & -168.608 & -243.788 & -189.917 \\ \text { BIC } & -95.384 & -207.176 & -137.615\end{array}$

\section{Panel D: Gold-Oil Dependence Structure}

AIC

$-212.133$

$-119.949$

$-130.545$

BIC

$-160.902$

$-97.337$

$-118.242$

${ }^{a}$ Note: The table reports the factor contributions for the Markov switching stochastic volatility models. Panels A to D report the factor contributions of the various dependence structures. The set of macroeconomic state variables include risk free rate, output gap, inflation, and risk aversion. The nonmacro factors are output uncertainty, inflation uncertainty, equity illiquidity measure, bond illiquidity measure, gold liquidity, term spread, variance premium and depth of recession. AIC is Akaike information criterion and BIC is Bayesian information criterion. 
Table 4: Forecasting performance of MSSV and non-regime switching stochastic volatility model

\begin{tabular}{|c|c|c|c|c|c|c|c|c|c|c|}
\hline \multirow{3}{*}{$\begin{array}{l}\text { Forecasted } \\
\text { Asset-Return } \\
\text { Comovements }\end{array}$} & \multicolumn{5}{|c|}{ Sample 1} & \multicolumn{5}{|c|}{ Sample 2} \\
\hline & \multirow{2}{*}{$\begin{array}{c}\text { MSE } \\
\text { (MSSV- } \\
\text { NRSM) }\end{array}$} & \multicolumn{2}{|c|}{$\alpha$} & \multicolumn{2}{|c|}{$\beta$} & \multirow{2}{*}{$\begin{array}{c}\text { MSE } \\
\text { (MSSV- } \\
\text { NRSM) }\end{array}$} & \multicolumn{2}{|c|}{$\alpha$} & \multicolumn{2}{|c|}{$\beta$} \\
\hline & & MSSV & NRSM & MSSV & NRSM & & MSSV & NRSM & MSSV & NRSM \\
\hline Equity-Bond & $\begin{array}{c}0.013 \\
(0.042)\end{array}$ & $\begin{array}{r}0.000 \\
(1.000)\end{array}$ & $\begin{array}{c}0.003 \\
(0.059)\end{array}$ & $\begin{array}{c}0.995 \\
(0.826)\end{array}$ & $\begin{array}{l}-0.248 \\
(0.038)\end{array}$ & $\begin{array}{c}0.014 \\
(0.011)\end{array}$ & $\begin{array}{c}0.000 \\
(1.000)\end{array}$ & $\begin{array}{c}0.004 \\
(0.049)\end{array}$ & $\begin{array}{c}0.968 \\
(0.113)\end{array}$ & $\begin{array}{c}2.514 \\
(0.028)\end{array}$ \\
\hline Equity-Real Estate & $\begin{array}{c}0.006 \\
(0.081)\end{array}$ & $\begin{array}{c}0.000 \\
(1.000)\end{array}$ & $\begin{array}{c}0.001 \\
(1.000)\end{array}$ & $\begin{array}{c}0.976 \\
(0.234)\end{array}$ & $\begin{array}{c}1.269 \\
(0.087)\end{array}$ & $\begin{array}{c}0.010 \\
(0.038)\end{array}$ & $\begin{array}{c}0.000 \\
(1.000)\end{array}$ & $\begin{array}{c}0.002 \\
(0.098)\end{array}$ & $\begin{array}{c}1.017 \\
(0.162)\end{array}$ & $\begin{array}{r}1.160 \\
(0.061)\end{array}$ \\
\hline Equity-Gold & $\begin{array}{c}0.036 \\
(0.024)\end{array}$ & $\begin{array}{r}0.000 \\
(1.000)\end{array}$ & $\begin{array}{c}0.002 \\
(0.099)\end{array}$ & $\begin{array}{c}1.013 \\
(0.808)\end{array}$ & $\begin{array}{l}3.245 \\
(0.000)\end{array}$ & $\begin{array}{c}0.082 \\
(0.019)\end{array}$ & $\begin{array}{c}0.000 \\
(1.000)\end{array}$ & $\begin{array}{c}0.000 \\
(1.000)\end{array}$ & $\begin{array}{c}1.019 \\
(0.166)\end{array}$ & $\begin{array}{r}0.016 \\
(0.000)\end{array}$ \\
\hline Equity-Oil & $\begin{array}{c}0.033 \\
(0.044)\end{array}$ & $\begin{array}{c}0.000 \\
(1.000)\end{array}$ & $\begin{array}{l}-0.001 \\
(1.000)\end{array}$ & $\begin{array}{c}1.042 \\
(0.178)\end{array}$ & $\begin{array}{c}1.590 \\
(0.025)\end{array}$ & $\begin{array}{c}0.053 \\
(0.068)\end{array}$ & $\begin{array}{c}0.000 \\
(1.000)\end{array}$ & $\begin{array}{c}0.028 \\
(0.031)\end{array}$ & $\begin{array}{c}0.962 \\
(0.411)\end{array}$ & $\begin{array}{c}0.141 \\
(0.000)\end{array}$ \\
\hline Bond-Real Estate & $\begin{array}{c}0.063 \\
(0.069)\end{array}$ & $\begin{array}{r}0.000 \\
(1.000)\end{array}$ & $\begin{array}{l}-0.001 \\
(1.000)\end{array}$ & $\begin{array}{c}0.898 \\
(0.181)\end{array}$ & $\begin{array}{c}7.295 \\
(0.000)\end{array}$ & $\begin{array}{c}0.003 \\
(0.029)\end{array}$ & $\begin{array}{c}0.000 \\
(1.000)\end{array}$ & $\begin{array}{c}0.001 \\
(1.000)\end{array}$ & $\begin{array}{c}1.009 \\
(0.922)\end{array}$ & $\begin{array}{c}0.308 \\
(0.000)\end{array}$ \\
\hline Bond-Gold & $\begin{array}{c}0.019 \\
(0.068)\end{array}$ & $\begin{array}{r}0.000 \\
(1.000)\end{array}$ & $\begin{array}{c}0.001 \\
(1.000)\end{array}$ & $\begin{array}{c}0.931 \\
(0.176)\end{array}$ & $\begin{array}{c}0.479 \\
(0.000)\end{array}$ & $\begin{array}{c}0.063 \\
(0.076)\end{array}$ & $\begin{array}{c}0.000 \\
(1.000)\end{array}$ & $\begin{array}{c}0.002 \\
(0.099)\end{array}$ & $\begin{array}{c}1.020 \\
(0.775)\end{array}$ & $\begin{array}{c}0.799 \\
(0.048)\end{array}$ \\
\hline Bond-Oil & $\begin{array}{c}0.049 \\
(0.014)\end{array}$ & $\begin{array}{r}0.000 \\
(1.000)\end{array}$ & $\begin{array}{c}0.000 \\
(1.000)\end{array}$ & $\begin{array}{c}0.900 \\
(0.102)\end{array}$ & $\begin{array}{l}18.045 \\
(0.000)\end{array}$ & $\begin{array}{c}0.020 \\
(0.049)\end{array}$ & $\begin{array}{c}0.000 \\
(1.000)\end{array}$ & $\begin{array}{c}0.000 \\
(1.000)\end{array}$ & $\begin{array}{c}0.984 \\
(0.870)\end{array}$ & $\begin{array}{c}0.217 \\
(0.000)\end{array}$ \\
\hline Real Estate-Gold & $\begin{array}{c}0.041 \\
(0.040)\end{array}$ & $\begin{array}{r}0.000 \\
(1.000)\end{array}$ & $\begin{array}{c}0.002 \\
(0.099)\end{array}$ & $\begin{array}{c}0.917 \\
(0.179)\end{array}$ & $\begin{array}{l}-0.461 \\
(0.006)\end{array}$ & $\begin{array}{c}0.025 \\
(0.028)\end{array}$ & $\begin{array}{c}0.000 \\
(1.000)\end{array}$ & $\begin{array}{c}0.000 \\
(1.000)\end{array}$ & $\begin{array}{c}0.909 \\
(0.176)\end{array}$ & $\begin{array}{c}2.781 \\
(0.000)\end{array}$ \\
\hline Real Estate-Oil & $\begin{array}{c}0.040 \\
(0.018)\end{array}$ & $\begin{array}{c}0.000 \\
(1.000)\end{array}$ & $\begin{array}{c}0.008 \\
(0.049)\end{array}$ & $\begin{array}{c}0.943 \\
(0.149)\end{array}$ & $\begin{array}{l}4.926 \\
(0.004)\end{array}$ & $\begin{array}{c}0.010 \\
(0.088)\end{array}$ & $\begin{array}{c}0.000 \\
(1.000)\end{array}$ & $\begin{array}{c}0.000 \\
(1.000)\end{array}$ & $\begin{array}{c}0.944 \\
(0.449)\end{array}$ & $\begin{array}{r}1.450 \\
(0.041)\end{array}$ \\
\hline
\end{tabular}




\section{Gold-Oil}

$$
0.012
$$

$$
0.000
$$

0.003

0.961

(0.048)

(1.000)

(0.057)

(0.149)

-0.056
$(0.000)$

Note: This table reports the difference between the median of square errors of MSSV models and the non-regime switching models (NRSM) and forecast efficiency regression estimates of the MSSV model and the non-regime switching model (NRSM). The parameters are estimated for two forecasting periods, i.e. Sample 1 and Sample 2. In sample 1, the models are estimated for the period 1987 to 2002 and forecasting is done for the period 2003 to 2012. In sample 2, the models are estimated for the period 2003 to 2012 and forecasted for the period 1987 to 1996. The forecasting estimates are calibrated for ten pairs of asset return comovements. It is evident that the MSSV model's median square errors are significantly lower than the non-regime switching models. This indicates that MSSV models outperform the non-regime switching models in out-of-sample forecasting of asset return comovements. This finding is observed for both the samples. The forecast efficient regression estimates show that the $(\alpha, \beta)$ values are not significantly different from $(0,1)$. In the forecast efficiency regression framework, if the mean and the variance forecast of the asset return comovements are unbiased, then the regression implies that $\alpha=0$ and $\beta=1$. However, the $(\alpha, \beta)$ estimates for the non-regime models are significantly different from $(0,1)$. The findings of $\alpha \neq 0$ and $\beta \neq 1$ indicate that the non-regime switching model forecasts either underestimates or overestimates the true volatility of asset return comovements or both during phases of high and low volatility in return comovements. The findings indicate that in contrast to the MSSV approach, the non-regime switching models yield biased forecasts. The standard errors are in parenthesis. 
Table 5: Below and above median forecasting performance of MSSV and non-regime switching stochastic volatility model

\begin{tabular}{|c|c|c|c|c|c|c|c|c|}
\hline \multicolumn{9}{|l|}{ Panel A: Sample 1} \\
\hline \multirow{3}{*}{$\begin{array}{l}\text { Forecasted } \\
\text { Asset-Return } \\
\text { Comovements }\end{array}$} & \multicolumn{4}{|c|}{ Below Median Forecast } & \multicolumn{4}{|c|}{ Above Median Forecast } \\
\hline & \multicolumn{2}{|c|}{$\alpha^{-}$} & \multicolumn{2}{|c|}{$\beta^{-}$} & \multicolumn{2}{|c|}{$\alpha^{+}$} & \multicolumn{2}{|c|}{$\beta^{+}$} \\
\hline & MSSV & NRSM & MSSV & NRSM & MSSV & NRSM & MSSV & NRSM \\
\hline \multirow[t]{2}{*}{ Equity-Bond } & 0.000 & -0.003 & 0.994 & 4.435 & 0.000 & 0.003 & 1.016 & -0.122 \\
\hline & 1.000 & 0.098 & 0.126 & 0.000 & 1.000 & 0.091 & 0.128 & 0.021 \\
\hline \multirow[t]{2}{*}{ Equity-Real Estate } & 0.000 & -0.001 & 0.952 & 12.887 & 0.000 & 0.000 & 0.977 & 0.307 \\
\hline & 1.000 & 0.109 & 0.101 & 0.000 & 1.000 & 1.000 & 0.107 & 0.000 \\
\hline \multirow[t]{2}{*}{ Equity-Gold } & 0.000 & -0.002 & 1.058 & 3.989 & 0.000 & 0.020 & 0.927 & 0.700 \\
\hline & 1.000 & 0.091 & 0.279 & 0.000 & 1.000 & 0.047 & 0.109 & 0.000 \\
\hline \multirow[t]{2}{*}{ Equity-Oil } & 0.000 & 0.018 & 1.015 & 2.301 & 0.000 & 0.002 & 0.989 & 0.046 \\
\hline & 1.000 & 0.015 & 0.100 & 0.000 & 1.000 & 0.102 & 0.126 & 0.000 \\
\hline \multirow[t]{2}{*}{ Bond-Real Estate } & 0.000 & 0.002 & 0.905 & 1.475 & 0.000 & 0.000 & 0.924 & 0.447 \\
\hline & 1.000 & 0.090 & 0.108 & 0.000 & 1.000 & 1.000 & 0.101 & 0.000 \\
\hline \multirow[t]{2}{*}{ Bond-Gold } & 0.000 & -0.004 & 0.938 & 1.907 & 0.000 & 0.000 & 0.903 & 0.029 \\
\hline & 1.000 & 0.092 & 0.112 & 0.000 & 1.000 & 1.000 & 0.100 & 0.000 \\
\hline \multirow[t]{2}{*}{ Bond-Oil } & 0.000 & 0.000 & 0.905 & 1.935 & 0.000 & 0.001 & 1.033 & 0.464 \\
\hline & 1.000 & 1.000 & 0.106 & 0.000 & 1.000 & 0.180 & 0.421 & 0.000 \\
\hline \multirow[t]{2}{*}{ Real Estate-Gold } & 0.000 & 0.000 & 1.027 & 5.600 & 0.000 & 0.003 & 1.038 & -4.116 \\
\hline & 1.000 & 1.000 & 0.546 & 0.000 & 1.000 & 0.091 & 0.604 & 0.000 \\
\hline \multirow[t]{2}{*}{ Real Estate-Oil } & 0.000 & 0.009 & 0.911 & 3.353 & 0.000 & 0.006 & 1.033 & 0.122 \\
\hline & 1.000 & 0.091 & 0.101 & 0.000 & 1.000 & 0.091 & 0.5067 & 0.046 \\
\hline Gold-Oil & 0.000 & 0.012 & 1.025 & 7.324 & -0.001 & 0.000 & 1.055 & -0.017 \\
\hline
\end{tabular}




\begin{tabular}{|c|c|c|c|c|c|c|c|c|}
\hline & 1.000 & 0.039 & 0.258 & 0.000 & 1.000 & 1.000 & 0.258 & 0.000 \\
\hline \multicolumn{9}{|l|}{ Panel B: Sample 2} \\
\hline \multirow{3}{*}{$\begin{array}{l}\text { Forecasted } \\
\text { Asset-Return } \\
\text { Comovements }\end{array}$} & \multicolumn{4}{|c|}{ Below Median Forecast } & \multicolumn{4}{|c|}{ Above Median Forecast } \\
\hline & \multicolumn{2}{|c|}{ Alpha } & \multicolumn{2}{|c|}{ Beta } & \multicolumn{2}{|c|}{ Alpha } & \multicolumn{2}{|c|}{ Beta } \\
\hline & MSSV & NRSM & MSSV & NRSM & MSSV & NRSM & MSSV & NRSM \\
\hline \multirow[t]{2}{*}{ Equity-Bond } & 0.000 & 0.004 & 1.019 & 7.531 & 0.000 & 0.007 & 0.981 & -0.593 \\
\hline & $(1.000)$ & $(0.091)$ & $(0.234)$ & $(0.000)$ & $(1.000)$ & $(0.091)$ & $(0.654)$ & $(0.000)$ \\
\hline \multirow[t]{2}{*}{ Equity-Real Estate } & 0.000 & 0.003 & 1.029 & 1.666 & 0.000 & 0.001 & 0.932 & -2.479 \\
\hline & $(1.000)$ & $(0.090)$ & $(0.595)$ & $(0.060)$ & $(1.000)$ & $(0.182)$ & $(0.288)$ & $(0.000)$ \\
\hline \multirow[t]{2}{*}{ Equity-Gold } & 0.000 & 0.000 & 1.017 & 0.986 & 0.000 & 0.003 & 0.986 & -0.017 \\
\hline & $(1.000)$ & $(1.000)$ & $(0.329)$ & $(0.372)$ & $(1.000)$ & $(0.091)$ & $(0.649)$ & $(0.029)$ \\
\hline \multirow[t]{2}{*}{ Equity-Oil } & 0.000 & 0.000 & 1.060 & 0.755 & 0.000 & 0.040 & 0.977 & -0.299 \\
\hline & $(1.000)$ & (1.000) & $(0.129)$ & $(0.047)$ & (1.000) & $(0.026)$ & $(0.329)$ & $(0.032)$ \\
\hline \multirow[t]{2}{*}{ Bond-Real Estate } & 0.000 & 0.000 & 1.017 & 1.591 & 0.000 & 0.000 & 0.987 & 0.169 \\
\hline & (1.000) & (1.000) & $(0.378)$ & $(0.000)$ & $(1.000)$ & $(1.000)$ & $(0.629)$ & $(0.000)$ \\
\hline \multirow[t]{2}{*}{ Bond-Gold } & 0.000 & 0.000 & 1.022 & 2.699 & 0.000 & 0.004 & 0.954 & -6.029 \\
\hline & $(1.000)$ & (1.000) & $(0.281)$ & $(0.000)$ & $(1.000)$ & $(0.091)$ & $(0.322)$ & $(0.000)$ \\
\hline \multirow[t]{2}{*}{ Bond-Oil } & 0.000 & 0.000 & 1.004 & 1.321 & 0.000 & 0.000 & 0.969 & 0.107 \\
\hline & (1.000) & (1.000) & $(0.529)$ & $(0.047)$ & $(1.000)$ & $(1.000)$ & $(0.627)$ & $(0.000)$ \\
\hline \multirow[t]{2}{*}{ Real Estate-Gold } & 0.000 & -0.001 & 0.908 & 5.070 & 0.000 & 0.000 & 0.989 & -0.667 \\
\hline & $(1.000)$ & $(0.091)$ & $(0.418)$ & $(0.000)$ & $(1.000)$ & $(1.000)$ & $(0.482)$ & $(0.002)$ \\
\hline \multirow[t]{2}{*}{ Real Estate-Oil } & 0.000 & 0.000 & 0.992 & 3.074 & 0.000 & 0.000 & 0.967 & 0.359 \\
\hline & $(1.000)$ & (1.000) & $(0.483)$ & $(0.000)$ & (1.000) & $(1.000)$ & $(0.258)$ & $(0.027)$ \\
\hline Gold-Oil & 0.000 & -0.030 & 1.017 & 2.469 & -0.001 & 0.010 & 0.955 & 0.408 \\
\hline
\end{tabular}


(1.000)

Note: This table reports the forecast efficiency regression estimates of the MSSV model and the non-regime switching model (NRSM). The parameters are estimated for two forecasting periods, i.e. Sample 1 and Sample 2. In sample 1, the models are estimated for the period 1987 to 2002 and forecasting is done for the period 2003 to 2012. In sample 2, the models are estimated for the period 2003 to 2012 and forecasted for the period 1987 to 1996. Panel A and Panel B report the forecast efficient regression estimates for Sample 1 and Sample 2, respectively. The forecasting estimates are calibrated for ten pairs of asset return comovements. For each of the samples the forecasting efficient regression is estimated allowing for a break in the regression at the median forecast. Therefore, the table reports the forecast efficiency regression estimates for below median $\left(\alpha^{-}, \beta^{-}\right)$and for above median $\left(\alpha^{+}, \beta^{+}\right)$. In this framework, if the mean and the variance forecast of the asset return comovements are unbiased, then the regression implies that $\alpha=0$ and $\beta=1$. For the $\operatorname{MSSV}$ model, the $\left(\alpha^{-}, \beta^{-}\right)$and the $\left(\alpha^{+}, \beta^{+}\right)$estimates are not significantly different from $(0,1)$. However, for the non-regime switching model the $\left(\alpha^{+}, \beta^{+}\right)$estimates are significantly different from $(0,1)$. In particular, it is evident that the $\beta^{+}$values are significantly less than one. This shows that in periods of high asset return comovements (economic contraction phase) return comovements. In a similar vein the positive $\beta^{+}$values during periods of low asset return comovements, suggests that the non-regime switching model underestimates the true variance of the return covariance during the economic expansion phase. Alternatively, the findings indicate that the non-regime switching models provide biased out-of-sample forecasts. This observation is consistent across both the samples. The standard errors are in parenthesis. 
Table 6: Economic value of forecasting asset return comovements

\begin{tabular}{|c|c|c|c|c|c|c|c|c|}
\hline & \multicolumn{3}{|c|}{ MCC Strategy } & \multicolumn{3}{|c|}{ Dynamic Strategy } & \multirow[b]{2}{*}{ WTP } & \multirow[b]{2}{*}{ p-value } \\
\hline & Mean & Std. Dev & SR & Mean & Std. Dev & SR & & \\
\hline \multicolumn{9}{|l|}{$\gamma=5$} \\
\hline $0.5 \%$ & 18.00 & 19.02 & 0.92 & 21.16 & 20.71 & 0.99 & 0.19 & 0.091 \\
\hline $1.0 \%$ & 17.25 & 18.26 & 0.89 & 19.80 & 19.79 & 0.95 & 0.36 & 0.071 \\
\hline $1.5 \%$ & 16.63 & 17.39 & 0.87 & 19.04 & 19.07 & 0.92 & 0.41 & 0.055 \\
\hline $2.0 \%$ & 15.89 & 16.34 & 0.85 & 18.72 & 19.00 & 0.88 & 0.56 & 0.046 \\
\hline $2.5 \%$ & 15.04 & 15.48 & 0.81 & 18.01 & 18.03 & 0.86 & 0.87 & 0.024 \\
\hline $3.0 \%$ & 14.34 & 14.18 & 0.80 & 17.80 & 17.62 & 0.84 & 1.24 & 0.001 \\
\hline $3.5 \%$ & 13.65 & 12.85 & 0.79 & 16.90 & 16.54 & 0.81 & 1.66 & 0.001 \\
\hline \multicolumn{9}{|l|}{$\gamma=10$} \\
\hline $0.5 \%$ & 10.71 & 11.10 & 0.92 & 14.69 & 14.33 & 0.99 & 0.11 & 0.092 \\
\hline $1.0 \%$ & 9.76 & 9.84 & 0.89 & 14.19 & 13.88 & 0.95 & 0.34 & 0.064 \\
\hline $1.5 \%$ & 8.66 & 8.23 & 0.87 & 13.34 & 12.87 & 0.92 & 0.39 & 0.059 \\
\hline $2.0 \%$ & 7.96 & 7.01 & 0.85 & 12.14 & 11.52 & 0.88 & 0.51 & 0.047 \\
\hline $2.5 \%$ & 7.36 & 6.00 & 0.81 & 11.14 & 10.04 & 0.86 & 0.53 & 0.040 \\
\hline $3.0 \%$ & 6.36 & 4.20 & 0.80 & 10.39 & 8.79 & 0.84 & 0.68 & 0.015 \\
\hline $3.5 \%$ & 5.66 & 2.73 & 0.79 & 9.14 & 6.96 & 0.81 & 0.82 & 0.007 \\
\hline \multicolumn{9}{|l|}{$\gamma=15$} \\
\hline $0.5 \%$ & 6.41 & 6.42 & 0.92 & 10.72 & 10.32 & 0.99 & 0.10 & 0.092 \\
\hline $1.0 \%$ & 5.81 & 5.40 & 0.89 & 9.60 & 9.05 & 0.95 & 0.32 & 0.080 \\
\hline $1.5 \%$ & 5.06 & 4.09 & 0.87 & 8.65 & 7.77 & 0.92 & 0.33 & 0.079 \\
\hline $2.0 \%$ & 4.57 & 3.02 & 0.85 & 7.90 & 6.71 & 0.88 & 0.47 & 0.041 \\
\hline $2.5 \%$ & 3.73 & 1.52 & 0.81 & 6.65 & 4.83 & 0.86 & 0.50 & 0.038 \\
\hline $3.0 \%$ & 3.65 & 0.81 & 0.80 & 5.80 & 3.33 & 0.84 & 0.56 & 0.022 \\
\hline $3.5 \%$ & 3.60 & 0.13 & 0.79 & 5.10 & 1.98 & 0.81 & 0.62 & 0.010 \\
\hline
\end{tabular}

Note: The table compares the performance of MCC strategy and the dynamic strategy. The portfolio formation starts with 16 years of information (1987 to 2002) and the investment period is from 2003 to 2012. The annualized mean, standard deviation and the Sharpe ratios are reported for both the strategies. It is evident that the dynamic strategy yields higher returns and is more volatile than the MCC strategy. However, the Sharpe ratios are higher for the dynamic strategy, suggesting that investors are better rewarded for their risky portfolios. The investors are assumed to have power utility function and constant relative risk aversion represented as $\gamma$. The Willing-to-pay (WTP) certainty equivalence measure computes the maximum fee $(f)$ an investor is willing to pay for holding a dynamic strategy over the other 
strategy. The last column reports the bootstrapped $p$-values of the hypothesis: $H_{n u l l}: W T P \leq 0$. The hypothesis is rejected for all the cases at 10,5 or 1 percent significance levels. The findings show that the dynamic strategy outperforms the MCC strategy.

$*, * *, * * *$ represents significance at 10,5 and 1 percent levels 
Figure 1: Time-path of the Dependence Structures ${ }^{\text {a }}$

\section{Panel A: Regimes of Equity-Gold Dependence Structure}
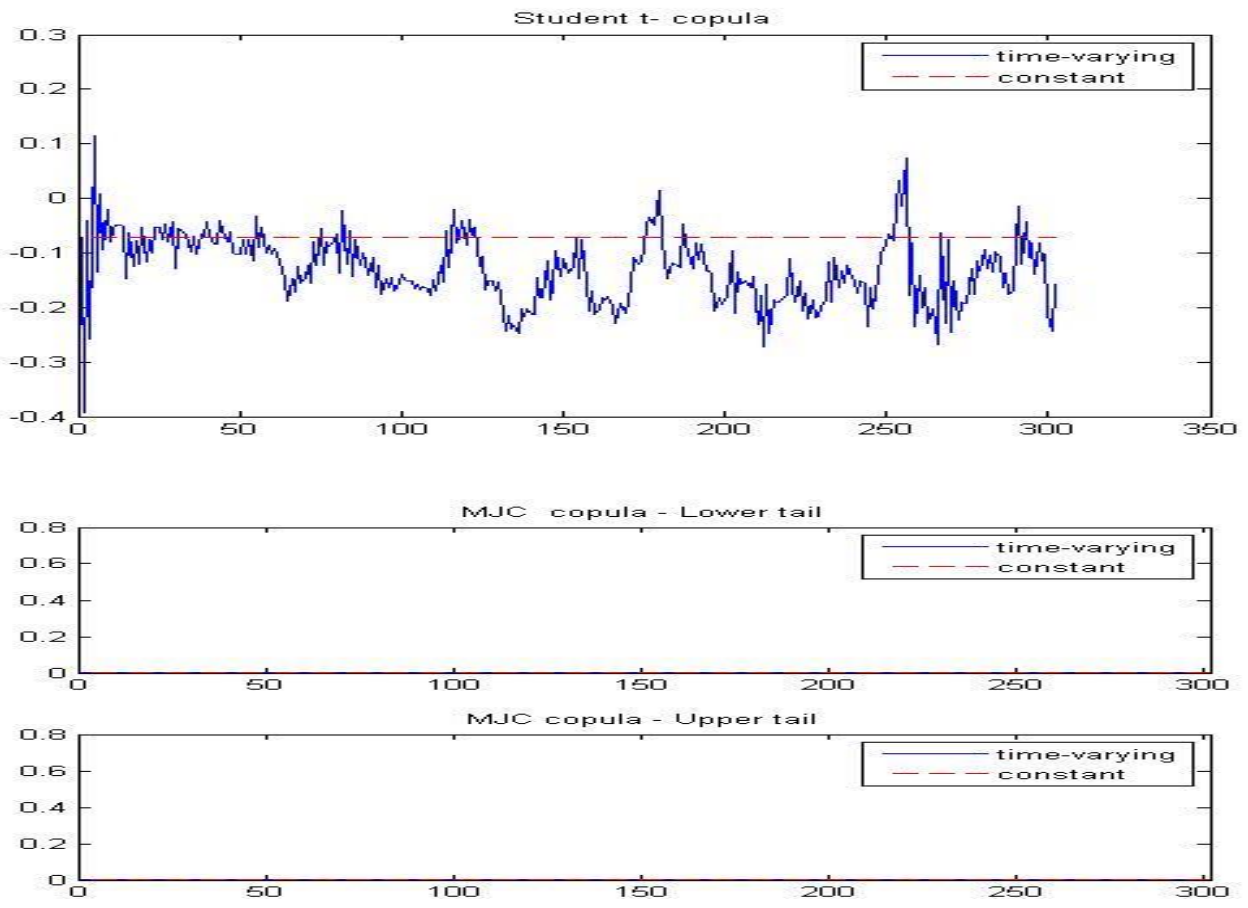

Panel B: Regimes of Bond-Gold Dependence Structure
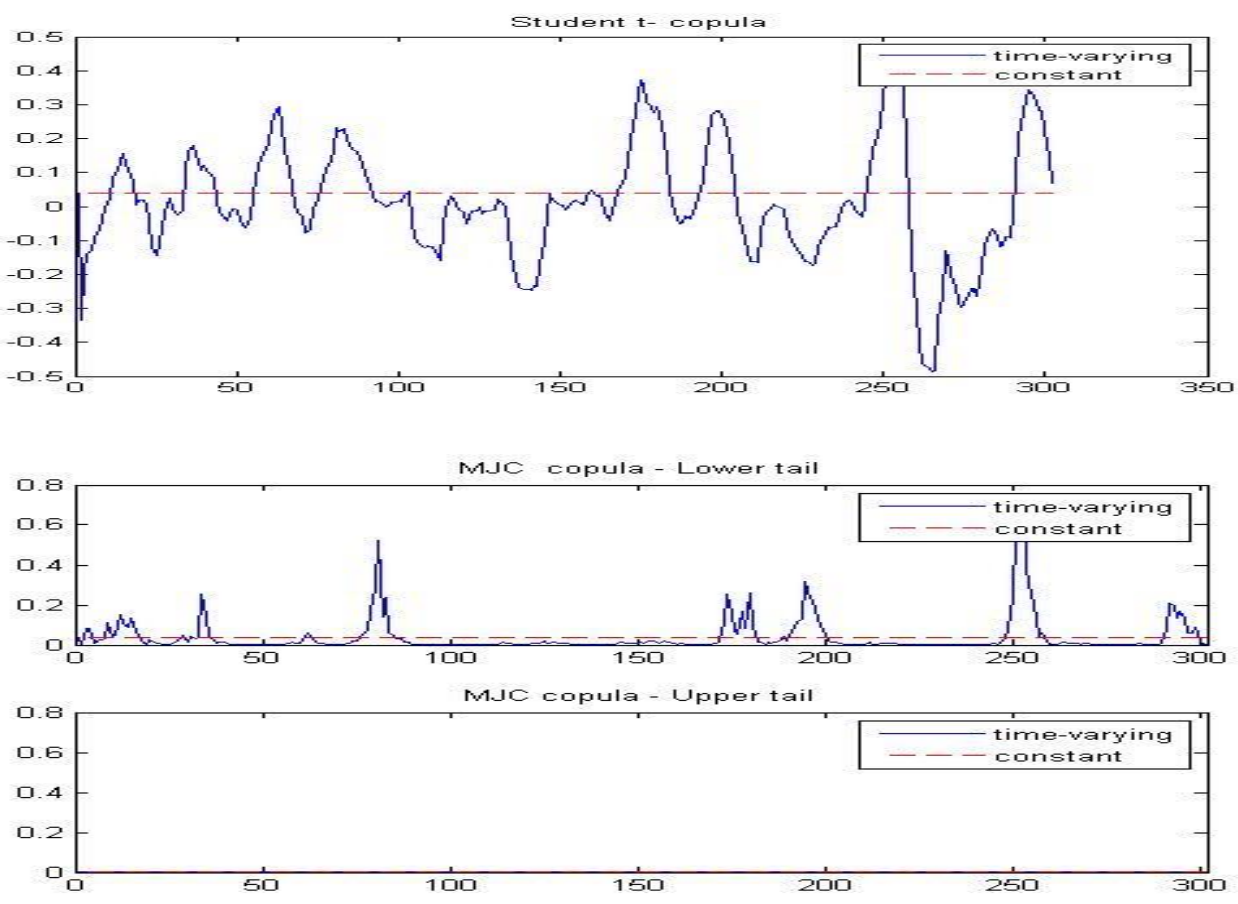


\section{Panel C: Regimes of Real estate-Gold Dependence Structure}
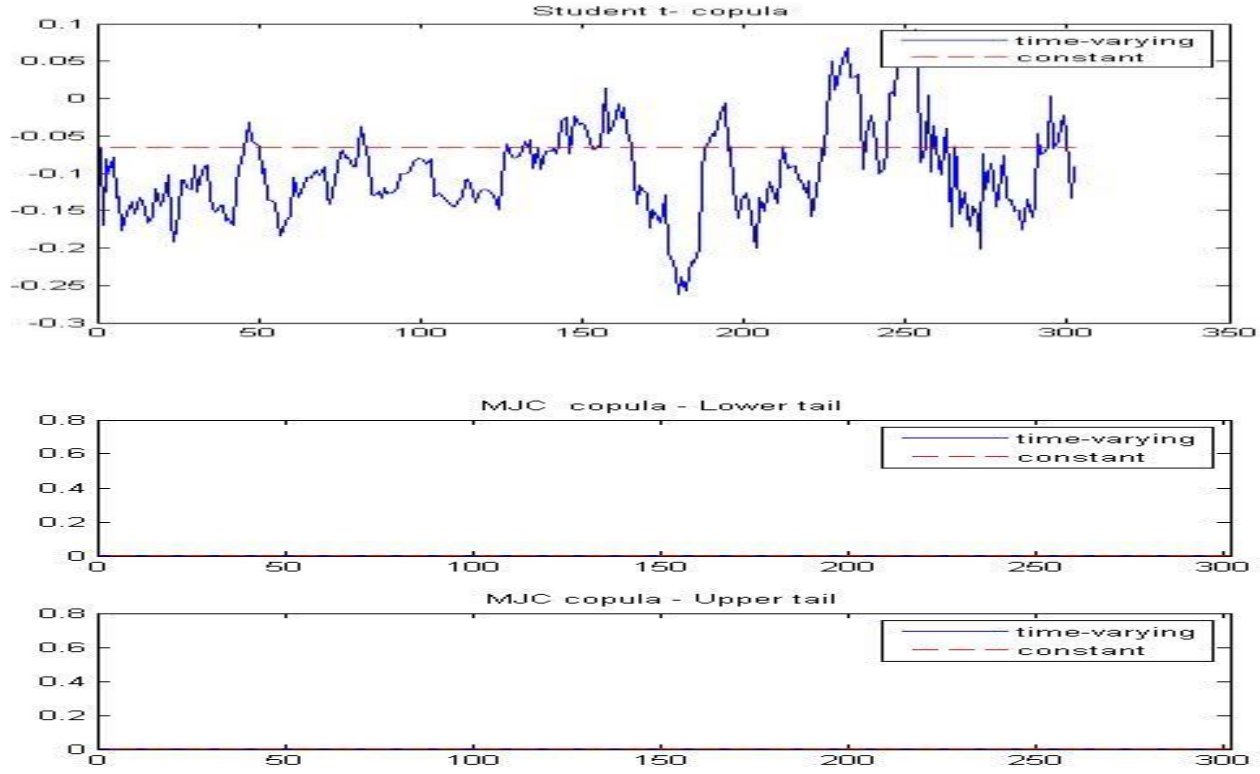

Panel D: Regimes of Gold-Oil Dependence Structure
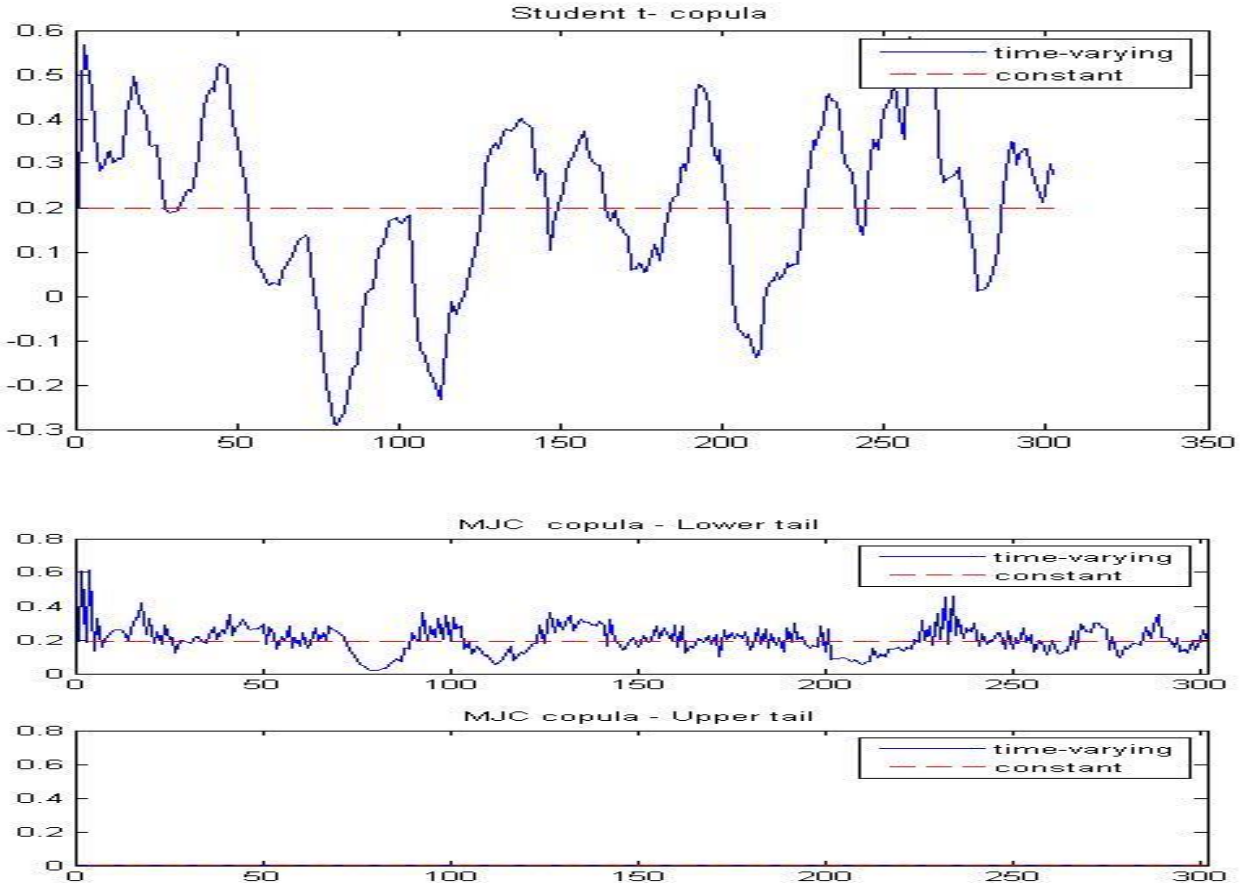

${ }^{a}$ Note: Panel A to D shows the time path of the time-varying dependence structure of the four asset-pairs. The average dependence measures for the period 1987 to 2012 of the different asset pairs are: Gold-Equity $(\mathrm{G} / \mathrm{E})=-0.047$, Gold-Bond $(\mathrm{G} / \mathrm{B})=0.029$, Gold-Real Estate $(\mathrm{G} / \mathrm{RE})=$ 0.091 and Gold and Oil $(\mathrm{G} / \mathrm{O})=0.180$. The average dependence measures for the asset pairs 
during the expansion period are: $\mathrm{G} / \mathrm{E}=-0.047, \mathrm{~B} / \mathrm{G}=0.027, \mathrm{~B} / \mathrm{O}=0.017, \mathrm{G} / \mathrm{RE}=-0.094$ and $\mathrm{G} / \mathrm{O}=0.162$. The average dependence measure for the asset pairs during the contraction period are: $\mathrm{G} / \mathrm{E}=-0.046, \mathrm{G} / \mathrm{B}=0.044, \mathrm{G} / \mathrm{RE}=-0.069$ and $\mathrm{G} / \mathrm{O}=0.321$. The lower tail corresponds to economic contractionary phase and the upper tail corresponds to economic expansionary phase. Here we compute the dependence structure of monthly return comovements to present a more informed description. 


\section{Appendix A}

\section{Estimation filter for the MSSV model}

The Kalman filter employed for projection is an iterative process. It forecasts the state variable at ' $t+1$ ' period and updates it when $z_{t}$ is observable in the equation (6). For deriving the filtering equations we denote:

$g_{t \mid t-1}^{(m, n)}=E\left[g_{t} \mid S_{t}=m, S_{t-1}=n, \psi_{t-1}\right], p_{t \mid t-1}^{(m, n)}=E\left[\left(g_{t}-g_{t \mid t-1}^{(m, n)}\right) \mid S_{t}=m, S_{t-1}=n, \psi_{t-1}\right]$

and $g_{t \mid t-1}^{m}=E\left[g_{t} \mid S_{t}=m, \psi_{t-1}\right], p_{t \mid t-1}^{m}=E\left[\left(g_{t}-g_{t \mid t-1}^{m}\right) \mid S_{t}=m, \psi_{t-1}\right]$

Following Smith (2002), we first forecast log-volatility and then update the previous forecasted estimate. The sequential steps are:

Step 1: The log-volatility is forecast using:

$$
\begin{aligned}
& g_{t \mid t-1}^{(m, n)}=\omega_{m}+\varphi_{m} g_{t \mid t-1}^{n} \\
& p_{t \mid t-1}^{(m, n)}=\varphi_{m}^{2} p_{t \mid t-1}^{n}+\sigma_{m}^{2}
\end{aligned}
$$

Step 2: The forecasted estimate is updated using

$$
\begin{gathered}
g_{t \mid t}^{(m, n)}=g_{t \mid t-1}^{(m, n)}+p_{t \mid t-1}^{(m, n)}\left(p_{t \mid t-1}^{(m, n)}+\frac{\pi^{2}}{2}\right)^{-1}\left(Z_{t}-Z_{t \mid t-1}^{(m, n)}\right) \\
p_{t \mid t}^{(m, n)}=p_{t \mid t-1}^{(m, n)}-p_{t \mid t-1}^{(m, n)}\left(p_{t \mid t-1}^{(m, n)}+\frac{\pi^{2}}{2}\right)^{-1} p_{t \mid t-1}^{(m, n)}
\end{gathered}
$$

The conditional densities are computed using the following equation

$$
\begin{aligned}
f\left(Z_{t} \mid S_{t}=m, S_{t-1}\right. & \left.=n, \psi_{t-1}\right) \\
& =\frac{1}{\sqrt{2 \pi\left(p_{t \mid t-1}^{(m, n)}+\frac{\pi^{2}}{2}\right)}}-\exp \left(\frac{-\left(Z_{t}-Z_{t \mid t-1}^{(m, n)}\right)^{2}}{2\left(p_{t \mid t-1}^{(m, n)}+\frac{\pi^{2}}{2}\right)}\right)^{-1} p_{t \mid t-1}^{(m, n)}
\end{aligned}
$$

It can be noted that the above procedures makes our process exclusively path dependent. Hence, to remove the path dependence we rely on Kim (1994) as stated in Smith (2002). We compute the conditional expectation of the log-volatility forecast by taking the weighted average output of the previous iteration using the formulations stated below. 


$$
\begin{gathered}
g_{t \mid t}^{m}=\frac{\sum_{n=1}^{N} \operatorname{Pr}\left[S_{t}=m, S_{t-1}=n \mid \psi_{t}\right] g_{t \mid t}^{(m, n)}}{\operatorname{Pr}\left[S_{t}=m \mid \psi_{t}\right]} \\
p_{t \mid t}^{m}=\frac{\sum_{n=1}^{N} \operatorname{Pr}\left[S_{t}=m, S_{t-1}=n \mid \psi_{t}\right]\left(p_{t \mid t}^{(m, n)}+\left(g_{t \mid t}^{n}-g_{t \mid t}^{(m, n)}\right)^{2}\right)}{\operatorname{Pr}\left[S_{t}=m \mid \psi_{t}\right]}
\end{gathered}
$$

We calculate the regime probabilities based on Smith's (2002) modification of Hamilton's (1989) filter. First, we estimate the regime probabilities using

$$
\operatorname{Pr}\left[S_{t}=m, S_{t-1}=n \mid \psi_{t}\right]=\operatorname{Pr}\left[S_{t}=m \mid S_{t-1}=n\right] \times \operatorname{Pr}\left[S_{t-1}=m \mid \psi_{t-1}\right]
$$

The term $\operatorname{Pr}\left[S_{t-1}=m \mid \psi_{t-1}\right]$ in the equation (A-8) is the previous iteration filter output. Next we calibrate the joint density using

$$
\begin{aligned}
f\left(Z_{t}, S_{t}=m, S_{t-1}=n \mid \psi_{t-1}\right) & \\
& =f\left(Z_{t} \mid S_{t}=m, S_{t-1}=n, \psi_{t-1}\right) \times \operatorname{Pr}\left[S_{t-1}=m \mid \psi_{t-1}\right]
\end{aligned}
$$

where $f\left(Z_{t}, S_{t}=m, S_{t-1}=n \mid \psi_{t-1}\right)$ is defined previously in equation (A- 5). In step three we integrate the regimes to calculate the unconditional density as given in equation (A-10) and then we update the probability of the regimes in state ' $t$ ' using equation (A-11).

$$
\begin{gathered}
f\left(Z_{t} \mid \psi_{t-1}\right)=\sum_{m=1}^{M} \sum_{n=1}^{N} f\left(Z_{t} \mid S_{t}=m, S_{t-1}=n, \psi_{t-1}\right) \\
\operatorname{Pr}\left[S_{t}=m, S_{t-1}=n \mid \psi_{t-1}\right]=\frac{f\left(Z_{t} \mid S_{t}=m, S_{t-1}=n, \psi_{t-1}\right)}{f\left(Z_{t} \mid \psi_{t-1}\right)}
\end{gathered}
$$




\section{Appendix B}

\section{Data Description}

Output Gap $\left(o_{t}\right)$ : Gross Domestic Product (GDP) is the measure of output. The gap is the percentage difference between the output and its expected output gap.

Expected Output Gap $\left(g_{e}\right)$ :It is estimated as

$E_{t}\left[g_{e}\right]=E_{t}\left[\frac{G D P_{t}}{G D P_{t}}\left(\frac{G D P_{t+1}}{G D P_{t+1}^{q t}}-1\right)\right]=G D P_{t} \frac{E_{t}\left[\frac{G D P_{t+1}}{G D P_{t}}\right]}{G D P_{t+1}^{q t}}$

Where $\mathrm{GDP}_{\mathrm{t}}$ is the level of real GDP at time $t$ and $G D P_{t+1}^{q t}$ is the quadratic trend value of real GDP. To measure $\left[\frac{G D P_{t+1}}{G D P_{t}}\right]$, the median of the survey response from Survey of Professional Forecasters (SPF) is used when available.

Output Uncertainty $\left(\mathrm{ou}_{t}\right)$ : Mean of SPF's real output volatility.

Inflation ( $i_{t}$ measured as $\pi$ ): Log difference of the Consumer Price Index (CPI) for all items for all urban consumers.

Expected Inflation $\pi_{e}$ : Treasury Inflation Protected (TIP) note subtracted from ten-year Treasury note

Inflation Uncertainty (iut measured as $\pi_{u}$ ): It will be estimated as the fractional uncertainty measure of inflation $\left[\frac{\pi_{e}-\pi}{\pi}\right]$.

Risk Aversion Factor $\left(\mathrm{ra}_{t}\right)$ : The measure of the risk aversion factor is based on external habit specifications of Campbell and Cochrane (1995) taken from Baele et al. (2010). The values are considered from Bekaert and Engstrom (2010).

Nominal Risk-free Rate $\left(R_{f}\right)$ : Three-month Treasury bill rate

Stock Market Illiquidity $\left(l r_{t}\right)$ : We first measure the trading intensity using turnover ratio. The quarterly turnover is calculated by dividing the total trading volume over a quarter by the average market value during the quarter. We then construct the illiquidity ratio as suggested by Amihud (2002), i.e. $l r_{t}=N^{-1} \sum_{N}\left(\left|R_{N t}\right| /\right.$ Turnover $\left._{N t}\right)$, where $\left|R_{N t}\right|$ is the absolute daily return, $\mathrm{N}$ is the number of trading days in a quarter $t$ and Turnover $_{N t}$ is the daily turnover of day $d$ in quarter $t$. We consider capitalization-based zero daily returns across all listed firms. Importantly, Amihud (2002) shows that this measure of illiquidity is highly positively correlated with the price impact that coincides with the bid-ask spread in standard-size transactions. Also, 
Hasbrouck (2009) shows that this illiquidity measure performs better than the other measure of liquidity.

Bond Market Illiquidity $\left(d s_{t}\right)$ : Bid-ask spreads across all securities, i.e. one month , three months, and one, two, three, five, seven, ten, twenty and thirty years of maturity.

Gold market liquidity factor $\left(G L I R_{t}\right)$ : The gold liquidity factor is estimated as the change in open interest

Variance Premium (vp): The difference between ex-post realized variance and variance swap rate.

Term Spread $\left(t s_{t}\right)$ : Difference between ten-year and three-month Treasury bill yields. This will serve as a proxy for short term economic condition.

Depth of recession $\left(d r_{t}\right)$ :It is based on Lee and Wang's (2012) estimate of business cycle proxy. 


\section{Appendix C}

\section{Turning Points in the Business Cycle}

\begin{tabular}{cccc}
\hline Turning Point & Date & Expansion (E)/Contraction (C) & Months in Phase \\
\hline 0 & $8 / 1987$ & E1 & 35 \\
1 & $7 / 1990$ & C1 & 8 \\
2 & $3 / 1991$ & E2 & 120 \\
3 & $3 / 2001$ & C2 & 8 \\
4 & $11 / 2001$ & E3 & 73 \\
5 & $12 / 2007$ & C3 & 18 \\
6 & $6 / 2009$ & E4 & 40
\end{tabular}

Notes: The turning points of the business cycle are based on the NBER-official dates of troughs and peaks (NBER, 2013). The sample period is from the fourth quarter of 1987 to the fourth quarter of 2012, yielding 302 monthly observations. Each month in the sample is divided into either an expansionary phase or a contractionary phase based on the turning point. The expansionary period has 268 months and the contractionary period has 34 months. 